\title{
MANIFESTACIONES INICIALES DE LA REPRESENTACIÓN EN EL RÍO DE LA PLATA: LA REVOLUCIÓN EN LA LABORIOSA BÚSQUEDA DE LA AUTONOMÍA DEL INDIVIDUO (1810-1812)
}

POR

\author{
JUAN CARLOS GARAVAGLIA \\ Ecole des Hautes Etudes en Sciences Sociales, Paris
}

Siguiendo el camino trazado por una serie de estudios sobre historia de las formas primigenias de representación en América ibérica, trataremos de mostrar de qué forma un análisis pormenorizado de primeras elecciones rioplatenses puede contribuir a enriquecer nuestro acercamiento al tema de la «representación política» y de la «ciudadania» durante los dos años iniciales post revolucionarios. Partiendo evidentemente de la «vacatio regis», tratamos de ver en este trabajo de qué modo las elites de Buenos Aires, que estaban conduciendo el único proceso que se mantuvo en forma independiente durante ese periodo, hicieron todo lo posible para que éste no escapara a su control. Efectivamente, lo consiguieron pero, a un precio que acarrearía graves consecuencias en la evolución posterior del área rioplatense.

PALABRAS CLAVES: Revolución de independencia, representación, ciudadanía, elecciones, "pueblos», ciudades principales, elites, grupos subalternos.

\section{INTRODUCCIÓN}

El tema de las elecciones durante siglo XIX —que en los últimos años varios libros han planteado en sus variables más generales para el conjunto de Iberoámerica ${ }^{1}$ - había sido hasta ese momento dejado casi completamente de lado por la historiografía en lo que hace al periodo inicial de ese siglo (se lo tomaba como

${ }^{1}$ Antonio AnNIno, (ed.), Historia de las elecciones en Iberoamérica, siglo XIX. De la formación del espacio politico nacional, Buenos Aires, FCE, 1995, [en adelante Historia de las elecciones]. Eduardo PoSADA CARBÓ, Elections before Democracy: The History of Elections in Europe and Latin America, Londres, Institute of Latin American Studies, 1996. Hilda SÁBATO, (ed.), Ciudadanía política y formación de las naciones. Perspectivas históricas de América Latina, México, FCE/El Colegio de México, 1999, [en adelante Ciudadanía política]. 
un ejercicio «inútil» y «no democrático» en el marco de una sociedad férreamente dominada por caudillos). Siguiendo el camino trazado por los estudios antes mencionados, trataremos de mostrar de que forma un análisis pormenorizado de estas elecciones iniciales puede contribuir a enriquecer nuestro acercamiento al tema de la representación política y la ciudadanía durante esos primeros años postrevolucionarios rioplatenses.

Dado que la vacatio regis ocasionada por los hechos de Bayona había dejado a las sociedades hispanoamericanas sin cabeza, toda construcción político institucional novedosa que la reemplazara debía tener como base de sustentación la representación de los pueblos ${ }^{2}$ (aún cuando la opinión monárquica fue más relevante de lo que la historiografía de inspiración patriótica generalmente ha aceptado $\left.^{3}\right)$. Pero, llegar a determinar qué englobaba exactamente ese término de los pueblos, no fue tarea simple - y ese larguísimo camino aún en nuestros días está lejos de haberse acabado ${ }^{4}$. De todos modos, muchos de los elementos que se repetirán, una y otra vez, en la historia posterior sobre este tema aparecen ya desde ese momento inicial: ¿Quiénes deben votar? ¿Cómo se debe ejercitar concretamente ese derecho? ¿Qué se puede votar? En consecuencia, el tema de su «representación» estuvo en el centro de casi todos los planteos políticos más decisivos de estas primeras décadas de la formación de los nuevos estados ${ }^{5}$. Varios autores han estudiado este momento para el Río de la Plata: la tésis de Pilar González Bernaldo, sostenida en 1992, discutía algunos aspectos del problema eleccionario en el periodo ${ }^{6}$. Un artículo posterior de José Carlos Chiramonte con la colaboración de Marcela Ternavassio y Fabián Herrero, «Vieja y nueva representación: los procesos electorales en Buenos Aires, 1810-1820»7 , marcó las líneas fundamentales de este problema en el ámbito de la ciudad de Buenos Aires - y en menor medida, también de la campaña-durante los años 1810/1820. El trabajo de Marcela Ternavassio «Nuevo régimen representativo y expansión de la frontera política...» $»^{8}$, seña-

2 Acerca de este aspecto de la cuestión, ver el estudio ya clásico de François-Xavier GuERRA, Modernidad e independencias. Ensayos sobre las revoluciones hispánicas, México, FCE/Mapfre, 1993.

3 Sobre el tema para el Río de la Plata, sigue siendo de lectura obligada el casi centenario libro de Adolfo SALDíAS, La evolución republicana durante la revolución argentina, Madrid, Editorial América, 1919.

4 Y no sólo en la experiencia latinoamericana, como lo señala Rossanvallon: «Le peuple est un maître indissociablement impérieux et insaisissable» [«El pueblo es un patrón indisociablemente imperioso e inasible»], Pierre Rossanvallon, Pour une histoire conceptuelle du politique, Paris, Seuil, 2002, p.16.

5 Remitimos a la presentación que hace José Carlos ChIARAMONTE de esta problemática en su «Estudio preliminar» a Ciudades, provincias, Estados: orígenes de la Nación Argentina (18001846), Buenos Aires, Ariel, 1997, en las pp. 111-124.

${ }^{6}$ Civilité et politique aux origines de la nation argentine. Les sociabilités à Buenos Aires, 1829-1862, Paris, Publications de la Sorbonne, 1999, en especial, pp. 112-116.

7 Historia de las elecciones [1], pp. 19-63.

8 Marcela TERNAVASSIO, «Nuevo régimen representativo y expansión de la frontera política. Las elecciones en el estado de Buenos Aires: 1820-1840», Historia de las elecciones [1], pp. 65-105. 
la las líneas generales de desarrollo del periodo que llega hasta 1840 en el ámbito rural bonaerense. Chiaramonte y Tarnavassio volvieron sobre el tema en el libro, coordinado por Hilda Sabato, Ciudadanía política ${ }^{9}$. Finalmente, Ternavasios publicó en 2002 su libro La revolución del voto. Política y elecciones en Buenos Aires, 1810-1852 ${ }^{10}$. También, para algunas otras de las nuevas naciones iberoamericanas, como México, Colombia y los paises andinos durante esa etapa temprana del siglo XIX, el tema ha sido objeto de varios estudios ${ }^{11}$. La reflexiones que siguen están estrechamente relacionadas con algunas de las principales hipótesis de los trabajos citados que abrieron indudablemente un primer y fértil camino en un tema muy poco estudiado hasta entonces.

\section{LAS MANIFESTACIONES INICIALES DE LA REPRESENTACIÓN EN EL PLATA}

En los considerandos de la resolución que crea la Gazeta, Moreno subrayaba «El pueblo tiene derecho a saber la conducta de sus Representantes», señalando que el futuro «Congreso General» exigía una «opinión pública» informada. Hemos estudiado en otra parte el problema de la formación de una nueva opinión y no repetiremos aquí nuestras principales conclusiones ${ }^{12}$. Nos concentraremos ahora exclusivamente en el tema de la representación.

Desde el acta misma del 25 de mayo, el llamado a una reunión de los representantes de cada Cabildo del interior para «establecer la forma de gobierno que se

9 José Carlos CHIARAMONTE, «Ciudadanía, soberanía y representación en la génesis del estado argentino (c. 1810-1852)»; Marcela TERNAVASSIO «Hacia un régimen de unanimidad. Política y elecciones en Buenos Aires, 1828-1850», Ciudadanía política, [1], pp. 94-116 y pp. 119-141, respectivamente.

${ }_{10}$ Buenos Aires, Siglo XXI Editores Argentina, 2002.

11 México: Antonio ANNINO, «Cádiz y la revolución territorial de los pueblos mexicanos 1812-1821», Historia de las elecciones [1], pp. 177-226; Marco BELLINGIERI, «Las ambigüedades del voto en Yucatán. Representación y gobierno en una formación interétnica, 1812-1829», idem, pp. 227-290. En el caso colombiano, estudios clásicos, como los de Bushnell habían ya planteado varios de estos problemas: David Bushnell, «Voter participation in the Colombian election of 1856», Hispanic American Historical Review, 51 (2), 1971. Algunos ejemplos andinos tempranos en Marie Danièlle DemÉLAS, «Modalidades y significación de elecciones generales en los pueblos andinos, 1813-1814», en Historia de las elecciones [1], pp. 291-313. El caso limeño en Victor Peralta, «El cabildo de Lima y la política en el Perú, 1808-1814», en Scarlett O'PHELAN GodOY, ed., La independencia del Perú: de los borbones a Bolivar, Lima, Pontificia Universidad Católica del Perú, 2001. Para Bolivia, ver Marta IrurozQui, A bala, piedra y pala. La construcción de la ciudadanía política en Bolivia, 1826-1952, Sevilla, Diputación de Sevilla, 2000 y Rossana BARRAGÁN, L'État qui pacte. Gouvernement et peuples. La configuration de l'État et ses frontières, Bolivie (1825-1880), Thèse de l'Ecole des Hautes Etudes en Sciences Sociales, Paris, 2002.

12 Ver nuestro trabajo «Los primeros senderos de la revolución: la opinión en los balbuceos de la independencia rioplatense (1806-1813)», Izaskun ÁlvAREZ CuARTERO y Julio SÁNCHEZ GóMEZ, editores, Visiones y revisiones de la independencia americana, Salamanca, Ediciones de la Universidad de Salamanca, 2003, pp. 113-145. 
considere mas conveniente», era un objetivo claro de la junta que había tomado el poder en Buenos Aires. El apartado X del acta del 25 de mayo dice: «que los referidos SS. [los miembros de la junta] despachen sin perdida de tiempo ordenes circulares a los Xefes de lo interior y demas a quienes corresponde, encargandoles muy estrechamente baxo de responsabilidad, hagan que los respectivos Cabildos de cada uno convoquen por medio de esquelas a la parte principal y mas sana del vecindario, para que formando un congreso de solos los que en aquella forma hubiesen sido llamados elijan sus representantes y estos hayan de reunirse á la mayor brevedad en esta Capital» ${ }^{13}$. Es así como se da inicio al momento augural en la búsqueda de la representación «de los pueblos» en el Río de la Plata. El 27 de mayo se vuelve sobre el tema en una circular de la junta, solicitando que cuanto «antes sea posible, se nombren y vengan a la Capital los Diputados» ${ }^{14}$ enunciados en el acta del 25.

Como se ve, este puñado de palabras mágicas (congreso, representantes, diputados) va desde entonces a reiterar su aparición en el lenguaje político rioplatense. Obviamente, eran viejas palabras castellanas ${ }^{15}$, pero, ahora comenzarán a adquirir lentamente nuevos significados. Teniendo siempre presente lo que decía Roland Barthes — «las palabras tienen una memoria segunda que se prolonga misteriosamente en medio de significaciones nuevas» - ${ }^{16}$, analizaremos algunos de estos cambios. ¿Qué quiere decir representación en el lenguaje de la época? Para Covarrubias ${ }^{17}$ representar es «hacernos presente alguna cosa con palabras o figuras que se fixan en nuestra imaginación; de ay se dixeron representantes los comediantes». Como vemos una primera definición del siglo XVII, estrechamente ligada al sentido primigenio de la palabra latina y utilizada generalmente en el ámbito teatral. El mismo Covarrubias nos da otra acepción que tiene que ver con el lenguaje jurídico «Representar, es encerrar en si la persona de otro, como si fuera el mesmo, para sucederle en todas sus acciones y derechos». Estas dos acepciones seguirían, por supuesto, teniendo vigencia y vuelven a aparecer en el Diccionario de Autoridades de $1726^{18}$, pero se abre ahora un abanico semántico más amplio. Retengamos estas dos: «Vale también informar, declarar o referir» y «Subrogarse en los

${ }^{13}$ La Revolución de Mayo a través de los impresos de la época, [en adelante RMAIE] compilados por Augusto E. MaLliÉ, Buenos Aires, Comisión Nacional Ejecutiva del 150 Aniversario de la Revolución de Mayo, 1965, tomo I, p. 353, apartado X del acta del 25 de mayo de 1810.

${ }^{14}$ RMAIE, tomo I, p. 365, «La Junta Provisional Gubernativa de la Capital de Buenos Ayres», $27 / 5 / 1810$.

15 Congreso aparece por vez primera en 1684 en castellano (siendo la palabra latina congressus, -us muy usual); diputado tiene su primera mención castellana en 1440 (existe un viejo verbo: diputar); representación tiene una antiguedad mayor aún en nuestra lengua, pues las primeras menciones remontan al siglo XIII. Ver Joan COROMINAS, Diccionario crítico etimológico castellano e hispano, Madrid, Gredos, 1989.

16 Roland BARTHES, El grado cero de la escritura, Buenos Aires, Jorge Alvarez, 1967, p. 20.

17 Sebastián de Covarrubias, Tesoro de la lengua castellana o Española, [1611], Barcelona, Alta Fulla, 1993.

18 Real Academia Española, Diccionario de Autoridades, [1726], Madrid, Gredos, 1990. 
derechos, autoridad y bienes de otro». En el Diccionario Castellano con las voces de Ciencias y Artes y sus correspondientes en las tres lenguas Francesa Latina e Italiana de $1788^{19}$, surge, muy tímidamente, un sentido un poco más cercano al que nos interesa; bajo la voz «Representación» podemos leer «súplica ó propuesta humilde que se hace á algún superior de los inconvenientes que se hallan en practicar este ó el otro decreto, edicto, \& ec. Fr. Remontrance. Lat. Suplicatio, repraesentatio. It. Supplica, representazione.» Está claro que esta acepción, si bien abre la puerta para un significado nuevo, tiene todavía el lastre de la «súplica respetuosa». Si vemos lo que trae la Encyclopedie de Diderot y d'Alembert para la palabra «représentants», podemos apreciar la distancia que hay entre este concepto y los precedentes : «Los representantes de una nación son los ciudadanos elegidos que, en un gobierno moderado, están encargados de hablar en su nombre, de estipular sus intereses, impedir que sea oprimida y contribuir a su administración» ${ }^{20}$.

Lo notable entonces es que no existe aún en el siglo XVIII una acepción claramente política de la palabra en castellano. María Teresa García Godoy, en su libro sobre el lenguaje político de la cortes gaditanas - comparado con el mexicano de la época ${ }^{21}$ _ , subraya que «representante del pueblo / de la nación» funciona como un sustituto léxico de diputado durante el periodo de las guerras de independencia (española y americanas). Ahora esta nueva significación nos remite entonces a diputado.

Diputado no existe en Covarrubias como término independiente, pero sí el verbo diputar, que lo incluye, como se verá: «Viene del verbo latino deputare, que vale cortar las ramas superfluas de los àrboles y los sarmientos inutiles viciosos de la vides y por alusion, a las cosas del ánimo». En realidad, Covarrubias toma aqui erróneamente uno de los dos sentidos que la palabra latina tenía, pues el otro, es decir, «evaluar, estimar», como señala el Gaffiot ${ }^{22}$ (y lo confirma Corominas), parece mucho más cercano a la idea que ya en el siglo XVII encerraba la palabra, dado que el mismo Covarrubias sigue diciendo «Y de aqui tomaron el

19 Editado por el padre Esteban de Terreros y PANDO, Madrid, Viuda de Ibarra, Hijos y Compañia, 1788.

20 «Les représentans d'une nation sont des citoyens choisis, qui dans un gouvernement tempéré sont chargés par la société de parler en son nom, de stipuler ses intérêts, d'empêcher qu'on ne l'opprime, de concourir à l'administration». El texto completo, por supuesto, es mucho más largo, ocupa casi 7 páginas y abunda en muy diversos aspectos del problema de la representación política tal como podía verse en Francia a fines del Antiguo Régimen ; ver Encyclopédie, ou Dictionnaire raisonné des Sciences, des Arts et des Métiers, par une Société de Gens de Lettres, Mis en ordre \& publié par M. Diderot, de l'Académie Royale des Sciences \& des Belles-Lettres de Prusse ; \& quant à la Partie Mathématique, par M. D'Alambert, de l'Académie Royale des Sciences de Paris, de celle de Prusse, \& de la Société Royale de Londres, A Paris, Chez Briasson, rue Saint Jacques, à la Science, David l'aîné, rue Saint Jacques, à la Plume d'or, Le Breton, Imprimeur ordinaire du Roy, rue de la Harpe, Durand, rue Saint Jacques, à Saint Landry, \& au Griffon, [1751/1765].

${ }^{21}$ María Teresa García Godoy, Las cortes de Cádiz y América. El primer vocabulario liberal español y mejicano (1810-1814), Sevilla, Diputación de Sevilla, 1998, pp. 242-244.

22 Félix GAFFIOT, Dictionnaire abrégé Latin-Français, Paris, Hachette, 1936. 
nombre los diputados, que son los escogidos para algún ministerio o particular o universal, como los diputados en la ciudad de Valencia y en otras partes». En Autoridades esta significación se consolida en diputar «Vale también destinar, señalar o elegir alguna o algunas personas, entre las que componen un cuerpo, para visitar algun sugeto de notable autoridad, tratar negocios o hallarse en algunas deliberaciones» y ahora sí, también en diputado: "Vale también Comissario u persona nombrada y destinada por un cuerpo u comunidad, para que en su nombre y con su autoridad execute alguna cosa». Como se observa en ambas, se destaca la elección por parte de «un cuerpo u comunidad», mostrando bien la concepción aneja a la «vieja» política que todavía tiene a inicios del XVIII, bien alejada de la idea de una asamblea de individuos que elige un representante. En el ya citado Diccionario Castellano con las voces de Ciencias y Artes... del padre Esteban de Terreros y Pando de 1788, vemos aparecer ahora un leve matiz de novedad «Diputación; especie de legacia o comission de alguno, ó algunos sujetos escogidos por un Principe, Asamblea ó cuerpo para este ó el otro negocio. Fr. Deputation, Lat. Legatio, It. Deputazione. El mismo nombre se da tambien á los mismos sujetos ó diputados», es decir, se incluye aqui también a una «Asamblea», entre los que pueden elegir una diputación. Como lo mencionamos, en la época de las cortes gaditanas se ha producido ya el desplazamiento representante/diputado, aun cuando la vieja concepción sigue coexistiendo a su lado. Congreso no aparece en Covarrubias, pero decíamos que la palabra latina congressus era usual en la acepción, ya clásica, de «encuentro» o «reunión». En Autoridades dice mucho más claramente «Junta, Assamblea formada para conferir, discurrir y resolver sobre assuntos» sin olvidar de agregar al final que era usual «especialmente, para ajustar paces», significado que continuó teniendo por supuesto. O sea, todas estas palabras congreso, representantes, diputados tenían ya su historia en el mundo ibérico.

\section{LOS CABILDOS ABIERTOS ${ }^{23} \mathrm{DE} 1810$}

Volvamos ahora a la citada circular del 27 de mayo de 1810; en ella, como dijimos, se enunciaba que «antes sea posible, se nombren y vengan a la Capital

${ }^{23}$ Usamos la expresión «cabildo abierto» porque las fuentes la utilizan en sus documentos, ver, por ejemplo, Rejistro Oficial de la República Argentina..., La República, tomo I, Buenos Aires, 1879, tomo II, Buenos Aires, 1880, [citado en adelante como RORA]; tomo I, p. 52 «este noble vecindario para que en cabildo abierto se ventilasen», Tucumán $26 / 6 / 1810$; RORA, tomo I, p. 85 «Habiendose congregado en esta Sala Capitular, todo su vecindario a Cabildo abierto», La Plata, 12/11/1810; Archivo General de la Nación, Buenos Aires [en adelante AGN], sala X-3-9-1 «se juntaron en esta sala capitular a celebrar el Cavildo abierto», Córdoba, 17/8/1810 AGN-X-3-9-1 «La que se ha verificado el 31 de agosto anterior en Cavildo Abierto», Catamarca, 5/9/1810 [subrayados nuestros en todos los casos]. También se los llama «cabildo general», Salta, RORA, tomo I, p. 38. En otros casos, la palabra utilizada es «congreso» o "asamblea», que nos remite a las reflexiones que apuntábamos precedentemente sobre estas voces castellanas. 
los Diputados» ${ }^{24}$. Esa circular, junto con una lacónica comunicación del depuesto virrey y otros impresos conexos, es enviada a los distintos Cabildos y autoridades del territorio virreinal ${ }^{25}$. Rápidamente, las respuestas comienzan a llegar a Buenos Aires; una de las primeras es la del Cabildo de Maldonado del 4 de junio y en ella se informa que «el Cabildo queda en realizar a la mayor brevedad la dispuesta convocación de vecinos para la eleccion de Diputados que debe pasar a esa Capital para asistir al Congreso general» ${ }^{26}$ y así, poco a poco, van llegando distintas respuestas. El primer problema se plantea en Santa Fe. En efecto, una comunicación del 19 de junio plantea una cuestión que sería después capital en todo tipo de elección: ¿quiénes tenían derecho a ser electores? La circular de la junta del 26 se refería a «la parte principal y mas sana del vecindario», pero la cuestión evocada por el cabildo santafesino demuestra que la cosa estaba lejos de ser evidente. Para los cabildantes, sólo los que «han obtenido empleos publicos» y «son vecinos de arraigo» tendrían derecho a voto; en cambio, otros consideran que los «puros jóvenes» también deben ser incluidos, pese a la oposición de los cabildantes (según éstos, los jóvenes serían «irreflexivos» en sus votaciones). La junta responde que «para la elección de Diputados deben citarse todos los vecinos existentes en la ciudad, sin distinción de casados o solteros» ${ }^{27}$. Como vemos, asoma aqui una concepción novedosa que apunta ya a la constitución de una asamblea de «participantes individuales» - y no corporativos - en estas primeras formas de representación. Esta propuesta de participación apunta más allá de la concepción tradicional de vecinos del mundo colonial ibérico («sin distinción de casados o solteros»), pese a que, paradojalmente, se da todavía en el marco de una corporación como el cabildo. Como se verá, esto se iría afirmando en forma progresiva.

Poseemos una documentación referida a esta elección para varias de las ciudades del espacio rioplatense y una comparación nos permitirá conocer mejor el «estado de la opinión» y las diferencias en cuanto a estas primeras formas de representación. Para las ciudades de Mendoza, San Juan, San Luis, Catamarca, La Rioja, Santa Fe, Corrientes, Santiago del Estero, Córdoba, Salta, Jujuy y Tarija contamos con los detalles de la elección ${ }^{28}$. Para Cochabamba, La Plata, Oruro

${ }^{24}$ RMAIE, tomo I, p. 365, «La Junta Provisional Gubernativa de la Capital de Buenos Ayres», $27 / 5 / 1810$.

${ }^{25}$ En los libros del Cabildo de Luján puede consultarse la circular que acompañaba a estos impresos, cf. Actas Capitulares, copia manuscrita realizada en el siglo XX, en Archivo Histórico «Estanislao Zeballos», Luján [en adelante AHEZ], acta del 9/6/1810,

${ }^{26}$ RORA, tomo I, p. 30.

${ }_{27}$ RORA, tomo I, pp. 37-38.

${ }^{28}$ La documentación completa en AGN-X-3-9-1; Ricardo Levene publicó una parte de esa documentación - concentrándo su análisis en el problema de los poderes otorgados a los diputados- en su Ensayo histórico sobre la Revolución de Mayo y Mariano Moreno, Buenos Aires, Facultad de Derecho y Ciencias Sociales, 1921, tomo II, pp. 428-500, con el delicado detalle de no mencionar la ubicación del documento original (i!). Las elecciones referidas a San Luis y San Juan habían sido publicadas ya, parcialmente, RORA, tomo I, pp. 46-48 y 53-56. Joaquín V. González 
y La Paz tenemos, en algunos casos, los nombramientos de diputados y en otros, la jura a la junta de Buenos Aires. Dejamos de lado aqui el caso de Asunción del Paraguay, pues su decidida política autonomista la coloca ya, desde julio de año $1810^{29}$, en una vía que muy rápido se convierte en independiente de los acontecimientos rioplatenses ${ }^{30}$.

Como se puede apreciar en el cuadro, desde la elección «consensual» realizada en Tucumán en favor del abogado Manuel Felipe de Molina en una reducida reunión a donde acuden sólo 36 personas (y en la cual los «vecinos» estrictamente hablando son realmente solo un puñado ${ }^{31}$ ) o la de Corrientes, en donde los «vecinos» no son realmente más que ocho, hasta la elección secreta a dos vueltas efectuada en Mendoza - con la asistencia de 165 votantes en la primera vuelta que decidirían entre ocho candidatos, estando los dos primeros casi empatados en número de votos - hay un mundo de diferencias, pese a hallarnos en todos los casos frente a un tipo de representación «antigua» realizada en el marco de una corporación como es el cabildo. Podemos hacer una distinción entre tres situaciones diversas.

Por un lado, los casos de San Miguel del Tucumán (y probablemente de La Rioja y Tarija) en los cuales la elección es resultado de un claro consenso previo entre los votantes que ni siquiera se corre el riesgo de ponerlo a prueba. Pocos votantes - y en Tucumán y Corrientes, pocos «vecinos» votantes - en relación a la población urbana que podemos evaluar para esos años con mayor o menor precisión. Tenemos después la situación más común: una votación «cantada» (es decir, llevada a cabo oralmente y en forma no secreta) con varios candidatos, sumada a la presencia un poco más consistente de «vecinos» ajenos a la conducción capitular. Podríamos, si quisiéramos hilar más fino, hacer una distinción entre, por un lado, San Luis y Jujuy —en los cuales parece haber habido real competencia entre los dos primeros-y todos las otras situaciones restantes, donde el consenso previo al momento de la reunión aparece bastante claramente delineado. También, dentro de esta categoría podríamos distinguir a Corrientes y a Santiago del Estero; en este caso, el número de los integrantes de la asamblea es bajo en relación a la cantidad de habitantes del casco urbano (compárese Corrientes con Jujuy y Santiago con San Juan, se advertirá así claramente la distancia que existe en ese sentido).

había tratado estas elecciones en Filiación histórica del gobierno representativo argentino, Buenos Aires, La Vanguardia, dos tomos, 1937.

${ }_{29}$ Ver RORA, tomo I, p. 56; respuesta del gobernador Velazco y del cabildo asunceno a la Junta de Buenos Aires, Asunción, 17 de julio de 1810.

30 cf. Juan Stefanich, «El Paraguay en la emancipación americana», Estudios Paraguayos, Revista de la Universidad Católica «Nuestra Señora de la Asunción», Asunción del Paraguay, vol III (2), diciembre de 1975, pp. 15-16.

31 En efecto, en Tucumán tenemos 7 cabildantes, 13 religiosos y 16 «vecinos distinguidos», AGN-X-3-9-1.

R. I., 2004, n. $^{\circ} 231$ 
CUADRO 1: Elecciones de 1810 para el nombramiento de diputados a Buenos Aires

\begin{tabular}{|c|c|c|c|c|c|}
\hline CIUDAD & $\begin{array}{c}\text { PARTICIPAN- } \\
\text { TES EN LA } \\
\text { VOTACIÓN }\end{array}$ & CANDIDATOS & $\begin{array}{c}1^{\circ} \mathrm{Y}^{\mathrm{o}} \\
\text { VOTADOS }\end{array}$ & $\begin{array}{c}\text { TIPO DE VO- } \\
\text { TACIÓN }\end{array}$ & $\begin{array}{c}\text { HABITANTES } \\
\text { URBANOS }\end{array}$ \\
\hline Salta & 102 & 11 & $\begin{array}{c}82 \text { votos } \\
4 \text { votos }\end{array}$ & $\begin{array}{c}\text { Voto } \\
\text { «cantado» }\end{array}$ & $\begin{array}{c}5.093 \\
{[1800]}\end{array}$ \\
\hline Jujuy & 75 & 4 & $\begin{array}{l}46 \text { votos } \\
18 \text { votos }\end{array}$ & $\begin{array}{c}\text { Voto } \\
\text { «cantado» }\end{array}$ & $\begin{array}{c}4.460 \\
{[1800]}\end{array}$ \\
\hline Tarija & 40 & $1[i ?]$ & $\begin{array}{c}38 \text { votos } \\
\text { ¿? }\end{array}$ & Consensual & $\mathrm{S} / \mathrm{D}$ \\
\hline Catamarca & 39 & $1[i ?]$ & $\begin{array}{c}39 \text { votos } \\
\text { ¿? }\end{array}$ & $\mathrm{S} / \mathrm{D}$ & $\begin{array}{c}5.971 \\
{[1800]}\end{array}$ \\
\hline La Rioja & 37 & $1[i ?]$ & no hay & Consensual & $\begin{array}{c}2.921 \\
{[1800]}\end{array}$ \\
\hline $\begin{array}{l}\text { Santiago del } \\
\text { Estero }\end{array}$ & 31 & 5 & $\begin{array}{c}23 \text { votos } \\
2 \text { votos }\end{array}$ & $\begin{array}{c}\text { Voto «can- } \\
\text { tado» }\end{array}$ & $\begin{array}{c}3.220 \\
{[1800]}\end{array}$ \\
\hline $\begin{array}{l}\text { San Miguel } \\
\text { de Tucumán }\end{array}$ & 36 & 1 & no hay & Consensual & $\begin{array}{c}3.640 \\
{[1800]} \\
\end{array}$ \\
\hline Corrientes & 28 & [11] & $\begin{array}{l}18 \text { votos } \\
7 \text { votos }\end{array}$ & $\begin{array}{c}\text { Voto «can- } \\
\text { tado» }\end{array}$ & 4.500 [est.] \\
\hline Sante Fe & 64 & 8 & $\begin{array}{l}45 \text { votos } \\
8 \text { votos }\end{array}$ & $\mathrm{S} / \mathrm{D}$ & 4.000 [est.] \\
\hline Córdoba & 100 & 3 & $\begin{array}{l}97 \text { votos } \\
1 \text { voto }\end{array}$ & $\begin{array}{c}\text { Voto } \\
\text { «cantado» }\end{array}$ & $\begin{array}{l}11.500 \\
{[1800]}\end{array}$ \\
\hline San Luis & 46 & 3 & $\begin{array}{l}29 \text { votos } \\
10 \text { votos }\end{array}$ & $\begin{array}{c}\text { Voto } \\
\text { «cantado» }\end{array}$ & $\begin{array}{c}1.716 \\
{[1812]}\end{array}$ \\
\hline San Juan & 87 & 6 & $\begin{array}{l}33 \text { votos } \\
24 \text { votos }\end{array}$ & $\begin{array}{l}\text { Secreta a } \\
\text { una vuelta }\end{array}$ & $\begin{array}{c}3.591 \\
{[1812]}\end{array}$ \\
\hline Mendoza & 165 & 8 & $\begin{array}{l}58 \text { votos } \\
51 \text { votos }\end{array}$ & $\begin{array}{c}\text { Secreta a } \\
\text { dos vueltas }\end{array}$ & $\begin{array}{c}5.487 \\
{[1812]}\end{array}$ \\
\hline
\end{tabular}

Y finalmente, tenemos los dos casos cuyanos de Mendoza y San Juan. Estos presentan características que no dudaría en llamar sorprendentes: votación secreta - con «cédulas» colocadas en una urna ${ }^{32}$ - entre varios candidatos, un número alto de votantes en donde los «vecinos» (quizás ya en un sentido más amplio, como el que señalábamos antes para Santa $\mathrm{Fe}$ ) son claramente la mayoría y, en el caso mendocino, la exigencia de una segunda vuelta, dado que «Para la mayor seguridad y pureza de los fines de la eleccion... se había acordado que de aque-

32 En realidad, se trataba de un cántaro «la Cedula en que llebaba escrito el nombre del sugeto de su inclinacion en un cantaro que al efecto estaba preparado...», AGN-X-3-9-1. 
llos sugetos que resultasen con el mayor numero de votos, fuesen dos o tres, se volviese a hacer nueva eleccion en uno para que en el recayese la verdadera y concurriere a ello todo el vecindario... $\rangle^{33}$. En Mendoza hay 165 votantes en la primera vuelta y 150 en la segunda, lo que indica una presencia de vecinos que va mucho más allá de los «vecinos distinguidos» de la mayor parte de las votaciones de las restantes ciudades. La elección sanjuanina es descripta con lujo de detalles por la Gaceta del 2 de octubre de 1810: «puesta una gran copa de cristal encima de la mesa, dio principio el Presidente poniendo en ella su cedula, siguiendole todos los vocales, prelados, cuerpos y noble vecindario a incorporar sus cédulas... practicada asi la eleccion, se dio orden al Escribano para que fuese leyendo cada una segun saliese y anotase el nombre de aquellos vecinos por quien se hubiesen sufragado». Además, en San Juan, se solicita incluso a las pequeñas villas dependientes (Jáchal y Valle Fértil) que den su opinión y participen en la nominación del diputado; éstas reúnen un número relativamente alto de vecinos convocados por jueces pedáneos a los efectos de aprobar la elección del representante sanjuanino ${ }^{34}$. Es decir, en San Juan en realidad participan efectivamente de la discusión un total de 139 vecinos $[87+27+25]$. No debe ser una casualidad esta «excepcionalidad» cuyana — iPodremos relacionarla en parte con la peculiar economía viñatera local y el tipo mediana propiedad que en general deriva de ella (dando lugar así a ámbitos de sociabilidad más «igualitarios», siempre en el marco estricto de las elites blancas)? - y no será tampoco un azar que la historia política de Cuyo sea tan peculiar en el marco rioplatense.

En fin, como podemos apreciar, pese a tratarse de una forma de representación «tradicional» y realizada en un marco corporativo como el del cabildo (es decir, en el marco pleno de lo que François-Xaver Guerra ha llamado «la política antigua ${ }^{35}$ ), se pueden observar diferencias que parecen estar ya profundamente enraizadas en las características de cada una de las sociedades locales en juego. Es decir, incluso en este cuadro, apegado todavía a las formas de la «vieja política», hay ya matices que apuntan a elementos de novedad; es notable, además, cómo estos matices tienen que ver en general con diferencias bastante evidentes de los diversos contextos sociales. Estas diferencias parecen surgir de lo más hondo de las sociedades locales concernidas. Como se puede ver, la búsqueda del

33 AGN-X-3-9-1.

34 En Jáchal los firmantes están encabezados por los dos jueces pedáneos — con funciones similares a los Acaldes de la Hermandad - más 25 vecinos; solo tres de los firmantes reciben el título de «don»; otro tanto ocurre en Valle Fértil donde son 27 los que firman y nuevamente hay tres agraciados con el «don», AGN-X-3-9-1.

35 Ver «De la política antigua a la política moderna. La revolución de la soberanía», en François- Xavier GUERRA, Annick LAMPÉRIÈRE, et al, Los espacio públicos en Iberoamérica Ambigüedades y problemas. Siglos XVIII-XIX, México, FCE, 1998. Ver asi mismo, en GuERRA [2], Modernidad e independencias, pp. 177-225, el análisis sobre las elecciones de 1809 en América. 
«ciudadano/individuo» ${ }^{36}$, procede en estos primeros balbuceos en forma lenta, pero continuada. Y en algunos casos, como comprobaremos seguidamente, se producirán pequeños - aunque significativos - cambios en lapsos muy cortos.

Tomemos el ejemplo de Salta. El 16 de junio de 1810, el cabildo salteño se reúne para tratar la comunicación de la junta porteña del 27 de mayo, más diversos impresos y el oficio de Cisneros y «atento a la gravedad de su contenido» y «teniendo por base la obediencia à nuestro Rey y Señor don Fernando Séptimo (que Dios guarde) Religión y Patria $\iota^{37}$ se decide diferir su tratamiento. Dos días más tarde, el 18 de ese mes, se vuelve a reunir el cabildo presidido ahora por el gobernador interino, Isasmendi. Se decide llamar a un «cabildo general» para el día siguiente. En ese día se expresan los votos individuales y en algunos casos, corporativos, de 61 personas. Los votos individuales son 22. Hallamos entre los votantes a algunos peninsulares destacados, como Juan Nadal y Guarda (pariente del cabildante de Buenos Aires, el catalán Jaime Nadal y Guarda) o Domingo de Santibáñez, que votarían claramente contra la junta porteña ${ }^{38}$, pero la mayoría de los restantes - entre los que se hallan hacendados como Francisco Javier Castellanos y José Vicente Toledo Pimentel - se «adhiere a la solicitud del Excelentisimo Cabildo de Buenos Aires». Los que lo hacen en forma corporativa son los abogados, los oficiales del Regimiento de Voluntarios encabezados por su jefe, el coronel $-\mathrm{y}$ hacendado - Pedro José Saravia, los capitulares, en asociación con los «ministros» de la Real Hacienda y finalmente, el obispo Nicolás de Vedia del Pino «por si y à nombre del venerable Dean y Cabildo Eclesiástico, curas rectores, prelados de las religiones y clerecía». El gobernador Isasmendi no tuvo más remedio que reconocer «la pluralidad de votos» y aceptar la decisión de la asamblea $^{39}$. Una asamblea de 61 individuos, de los cuales solo 21 han votado en forma individual y los restantes lo han hecho en forma corporativa.

El 31 de agosto, se realizan ahora las elecciones para el diputado a la «junta grande ${ }^{40}$. Esta elección «de Diputados para el Congreso Universal de estas Provincias para la capital de Buenos Ayres», fue mucho más concurrida que la asamblea precedente, pues hay 102 votantes y solo un puñado, 5 en total, delegaron su voto en forma corporativa. Se votó por 11 candidatos, pero, era evidente que había un fuerte consenso en la figura del doctor Francisco Gurruchaga que

${ }^{36}$ Cf. Pierre Rosanvallon, «L'individu autonome» en Le sacre du citoyen. Histoire du suffrage universel en France, Paris, Gallimard, 1992.

37 RORA, tomo I, p. 38

${ }^{38}$ El segundo de ellos, para que no queden dudas, se refiere en su voto a la «defensa del Rey, la Religión y la Patria», RORA, tomo I, p. 39.

39 Ver RORA, tomo I, pp. 38-40. Hay que señalar que una proclama de Nieto del 23 de junio, incluye al gobernador intendente de Salta entre los fieles al rey, Mayo Doc, tomo XII, Buenos Aires, 1966, pp. 65-69. Una carta de Chiclana del 1/9/1810 a la Junta de Buenos Aires señala que la posición de Isasmendi al reconocer a la Junta es más «por odio al Cavdo. qe por amor a ntra. causa», cf. LEVENE [23], Ensayo histórico sobre la Revolución de Mayo, tomo II, p. 401

40 AGN-X-3-9-1. 
obtuvo 82 votos; los restantes parecen ser votos de mera simpatía personal, pues sólo el licenciado Mateo Saravia obtuvo 4 sufragios, los restantes se distribuyen entre 9 personas ${ }^{41}$. No es una elección discutida, como vimos que ocurre en otras ciudades, pero estamos ante una representación más amplia que la predecente y que ha abandonado casi totalmente el voto corporativo. No debió ser ajeno a ello que la elección se haya hecho según «la orden circular para el metodo que debe observarse en ella» ${ }^{42}$. Y en efecto, la junta había circulado el 18 de julio instrucciones para que señalar cuáles eran las «cualidades personales» de los diputados, previniendo que se respetara para ello... la Real Orden del 6 de octubre de 1809 para la elección a Cortes $^{43}$. Esta influencia de algunos elementos institucionales surgidos del proceso revolucionario gaditano (también el juramento a la Asamblea de 1813, estará inspirado en el gaditano de $1810^{44}$ ) que no ha sido muy trabajada para el caso rioplatense ${ }^{45}$, abre insospechadas vías para entender mejor los primeros procesos eleccionarios en el Río de la Plata independiente, y nos muestra de qué modo se van incorporando nuevos estilos de hacer política abrevando en fuentes y experiencias muy diferentes. Como se puede apreciar en el caso salteño, en poco más de dos meses, en el mismo ámbito - pero ahora con la presencia de Feliciano Chiclana, un hombre enviado por la junta de Buenos Aires y que, como lo muestran algunas de sus cartas, se activó rápidamente en función de profundizar los cambios auspiciados desde la capital porteña durante los dos periodos en los que ocupó el cargo de Gobernador Intendente de Salta ${ }^{46}$ - se produce un leve y sin embargo, relevante, desplazamiento en las formas de realizar estas mismas reuniones en el marco «corporativo» del cabildo.

Es sabido cuál fue el destino final de estos diputados así elegidos; integrarían la llamada «Junta Grande» y esa incoporación daría pie a la renuncia de Mariano Moreno en diciembre de 1810, ante lo que considera una maniobra del grupo más cercano a Saavedra. En realidad, la iniciativa surgió del dean Funes, pero el presi-

${ }^{41}$ Los individuos y sus votos son: Mateo Saravia 4; Mariano Plácido Sánchez 3; Pedro Antonio Arias 2; Gabino Blanco 2; José Gabriel de Figueroa 2; José Fco. Tineo 2; Cayetano Zavala 2; Hermenegildo Hoyos 1; el Deán 1; Juan Thomás Forcada 1, ver AGN-X-3-9-1.

42 AGN-X-3-9-1, fjs. 18 vta.

${ }^{43}$ RORA, tomo I, p. 56; no sabemos exactamente a cuál Real Orden se refiere, pues conocemos las del 22/5/1809, en RMAIE, tomo I, pp. 115-117 y la del 7/1/1810, en Mayo Doc, tomo XI, pp. $14-29$

44 Cf. Nuestro artículo, ya citado «Los primeros senderos de la revolución: la opinión en los balbuceos de la independencia rioplatense (1806-1813)», Izaskun ÁlvAREZ CUARTERO y Julio SÁNCHEZ GómEZ [12].

45 Uno de los primeros estudios que lo señalan es el artículo citado de José Carlos CHIARAMONTE, realizado con la colaboración de Marcela TERNAVASSIO y Fabian HERRERO, «Vieja y nueva representación: los procesos electorales en Buenos Aires, 1810-1820», en Historia de las elecciones [1], pp. 19-63.

46 Ver Atilio CoRnEJo, Apuntes históricos sobre Salta, Buenos Aires, Instituto «San Felipe y Santiago»» de Estudios Históricos de Salta, 1937; Levene [23], Ensayo histórico sobre la Revolución de Mayo, tomo II, pp. 401-403 y el Epistolario belgraniano, Taurus, Buenos Aires, 2001, pp. 200-224. 
dente de la Junta no parece haber sido ajeno a ella. En efecto, el canónigo Juan Ignacio Gorriti, diputado por Jujuy en ese entonces, recuerda en su breve autobiografía $^{47}$ el papel de Saavedra en ese incidente de la incorporación de los diputados a la Junta. Es decir, el proyectado «Congreso» no tuvo efectivamente lugar, pues los diputados se integraron como miembros del poder ejecutivo. Ya desde antes, la Junta porteña había limitado claramente la extensión de la representación al restringirla exclusivamente a las «villas cabeceras de partido». En efecto, el 16 de julio de 1810, la Junta envía a todas las villas subalternas una circular resolviendo «se suspenda por ahora, la eleccion de Diputados en la villas que no sea cabeceras de partido hasta que se resuelva con detenido examen de la materia, si deben efectivamente tener representacion en el Congreso ${ }^{48}$. El cabildo de la villa de Luján, por ejemplo, toma conocimiento en forma oficial de esta comunicación en ocasión de su reunión del 23 de julio y decide asi suspender «la eleccion de Diputado qe. estaba proxima a verificarse ${ }^{49}$. Es obvio que esta suspensión, que debe ser entendida en función de los esfuerzos de Buenos Aires para que los acontecimientos inaugurados en mayo de 1810 no escapasen totalmente a su control, ante un proceso inevitable de dispersión de la soberanía, nos ha dejado sin una rica documentación referida a las mas pequeñas circunscripciones rurales (en todo caso como vimos, en las villas de Jáchal y Valle Fértil — dependientes de San Juan — se efectúa, en agosto de 1810, la votación para la elección de diputado).

\section{La situación de los cabildos abiertos altoperuanos}

En medio de la guerra ya instalada en la región, los cabildos de las ciudades cabeceras del Alto Perú, también participaron en esta primera etapa electoral desatada desde Buenos Aires (hay que recordar que los levantamientos altoperuanos precedieron en más de un año al golpe de estado porteño del 25 de mayo de $1810^{50}$ ). Contamos en primer lugar, con la documentación acerca de los cabildos abiertos que alcanzaron a reconocer a la Junta de Buenos Aires y es interesante mostrar algunas diferencias. De todos los casos, el más relevante por la amplitud de los «vecinos» llamados a integrar la asamblea en el acto de reconocimiento, es el de La Plata ${ }^{51}$. En efecto, el 13 de noviembre de 1810, el documen-

47 «Autobiografía política», manuscrito sin fechar y publicado con ese nombre por Miguel Angel Vergara en Papeles del Dr. Juan Ignacio de Gorriti, Jujuy, 1936.

48 RORA, tomo I, p. 56

49 Cabildo de Luján, acta capitular del 23 de julio de 1810, en AHEZ.

50 Cf. René Arze, Participación popular en la independencia de Bolivia, La Paz, Quipus, 1987.

51 Recuerde el lector que esta ciudad tenía tres nombres en estos años: La Plata, Charcas y Chuquisaca. Evitemos cualquier confusión con la ciudad bonaerense fundada un siglo más tarde; la documentación de esos años usa generalmente «La Plata» casi como nombre oficial para la ciudad, pero habla de Charcas al referirse a la Audiencia y sus habitantes son los chuquisaqueños. Para 
to afirma «Habiendose congregado en esta Sala Capitular, todo su vecindario a Cabildo abierto» y la expresión «todo su vecindario» no parece aquí usada inútilmente, pues contamos 195 firmantes en al acta de ese día; mas, parece evidente que se respeta aqui aún la acepción tradicional del término «vecino» ${ }^{52}$. También tenemos datos sobre otros cabildos altoperuanos, pero la información es mucho más parca ${ }^{53}$. De todos modos, la impresión general es que aquí también este periodo dio lugar a cambios importantes en función de la búsqueda de una nueva forma de representación. Esa impresión se acentúa si nos referimos ahora a la experiencia de la elección de diputados que se realizará en algunas de las ciudades más importantes del Alto Perú.

Uno de los casos interesantes es, nuevamente, el de La Plata. Aqui llega, el 27 de diciembre de 1810, viajando desde Potosí, Juan José Castelli, el enviado de la junta porteña. Había dejado en la ciudad minera al teniente coronel Pedro Lobo, como encargado del gobierno en espera de Feliciano Chiclana ${ }^{54}$, quien llegaba desde Salta donde había ejercido la gobernación intendencia, como ya hemos visto. De inmediato procede Castelli a organizar la elección para los diputados al congreso («congreso nacional $»^{55}$ que, entre tanto, se hallaba todavía en el aire, dado que, como ya se vió, los enviados que ya estaban en Buenos Aires integraron la Junta Grande y no se constituyeron realmente en «asamblea»). El 1 de febrero se realiza la elección en la sala capitular y un pequeño incidente nos permite conocer la forma en que ésta se realizó. Dos de los oidores de Charcas, el conde de San Javier y José Felix de Campo Blanco (el primero de ellos, regente, pero en funciones de presidente de la Audiencia), colocan en la «vasija» destinada a recoger los votos, sus papeletas en blanco. Una comunicación del cabildo a Castelli de ese mismo día, relata con lujo de detalles el incidente y agrega al final, las dos papeletas que se hallan inclusas en el legajo ${ }^{56}$. Esa dos papeletas rectangulares están firmadas - este hecho es posterior y efectuado probablemente durante el conteo de los votos- por tres de los capitulares. El documento describe detalladamente el incidente: «el Sor. Campoblanco descubrió el adjunto papel (qe. va señalado con el N. $1^{\circ}$ y rubricado pr. tres regidores) dando vuelta por uno y otro lado, con cuyo motivo y el de no doblarlo el poner en la vasija, repararon los individuos mas inmediatos qe. no havia letra alguna en el».

hacer la cosas más complicadas, hoy, como es notorio, la ciudad lleva el nombre «Sucre», en homenaje al mariscal Antonio José de Sucre.

52 RORA, tomo I, pp. 85- 87.

53 RORA, tomo I, pp. 78 [Cochabamba], $92-93$ [Oruro], 87 y 95 [La Paz].

${ }^{54}$ Consultar la larga carta de Castelli a la Junta del 10/1/1811, en AGN-X-3-10-2.

${ }^{55} \mathrm{La}$ Junta Grande seguía solicitando la concreción de estas elecciones en función de la reunion del «augusto Congreso Nacional», ver, por ejemplo, la circular del 27/2/1811, en AGN-X-3-4-2.

${ }^{56}$ La comunicación del cabildo a Castelli es del 1/2/1811, en AGN- X-3-10-2. 
Si recordamos que el «secreto es la marca irreductible del derecho a la individualidad $»^{57}$, esta peripecia electoral ilumina bastante bien la complejidad del proceso de construcción del individuo como actor político y el papel indudablemente relevante que juega el secreto en ese proceso. Recuérdese que las nuevas formas de publicidad poseen un carácter que puede parecer paradógico a simple vista, si las relacionamos con el secreto en el acto electoral. En efecto, estamos lentamente saliendo de una sociedad de Antiguo Régimen en donde «El secreto [era] la norma, solo [resultaban] visibles los gestos intencionales que [habían] sido librados al público» ${ }^{58}$. Justamente, son esas formas de opacidad de la res publica las que están entrando en crisis lentamente, pues éste es el momento en que «A la práctica del secreto se le opondrá [... ] el principio de la publicidad» ${ }^{59}$. Pero este principio de la publicidad sólo puede existir con verdadera fuerza si se basa en la autonomía del individuo/ciudadano. Y ella sólo puede estar a resguardo gracias al secreto de la votación individual. La «nueva» publicidad rompe el secreto en el que estaba envuelta la cosa pública, pero sólo lo puede hacer eficazmente a través del secreto del acto electoral...

Volvamos a La Plata. San Javier y Campo Blanco ya habían actuado en la precedente votación cuando se acató a la Junta porteña el 13 de noviembre - aparecen en la lista de participantes en el primer lugar, uno antes y el otro después del Arzobispo. Además, el conde de San Javier, como regente de la Audiencia, había ya dado muestras de su opinión contraria a la Junta porteña con una picardía típica de las luchas políticas de Antiguo Régimen: subrepticiamente le ordenó al portero que quitase durante la noche el sillón ceremonial dispuesta para el general Balcarce en la catedral, pese a haber acordado con Castelli el ceremonial para el Te Deum. Función ésta que se realizaría en la mañana del 8 de enero a los efectos de consolidar el nombramiento del militar porteño como presidente de la Audiencia ${ }^{60}$. Ya sabemos que la conflictualidad política de Antiguo Régimen tiene en el ceremonial y la etiqueta un vasto campo de acción ${ }^{61}$. Pero, volvamos al incidente. Es obvio que estos dos votantes manifestaron «abiertamente» su intención de votar en blanco - colocaron la papeleta de tal modo que todos viesen que no tenían ningún nombre inscripto. El hecho de que esos votantes fuesen quienes eran (como decíamos, no por casualidad encabezan junto con el Arzobispo la lista de

57 Cf. «L'individu autonome» en Rosanvallon [36], Le sacre du citoyen, p. 250.

58 Arlette FARGE, Dire et mal dire. L'opinion publique au XVIIIe siècle, Paris, Editions du Seuil, 1992, p. 98.

59 Jürgen HABERMAS, Historia y crítica de la opinión pública. La transformación estructural de la vida pública, Barcelona, G.Gili, 1997, p. 89.

60 Ver los detalles de estos acontecimientos en la carta del 10/1/1811, en AGN- X-3-10-2.

${ }^{61}$ Consultar nuestro trabajo «El teatro del poder: ceremonias, tensiones y conflictos en el estado colonial», Boletín del Instituto de Historia Argentina y Americana «Dr. Emilio Ravignani», 3a. serie, número 14, pp. 7-30, Facultad de Filosofía y Letras, UBA, Buenos Aires, 1996, ahora incluído en Juan Carlos Garavaglia, Poder, conflicto y relaciones sociales. El Río de la Plata, XVIII-XIX, Rosario, Homo Sapiens, 1999, pp. 123-155. 
noviembre de 1810) le daba a ese acto un valor simbólico muy grande. Todos podían saber que ellos no habían votado a los candidatos «oficiales». Esto es todo lo contrario de un acto secreto y su publicidad cumple aquí la función reveladora de ser, sino no amenaza, al menos una clara advertencia. (justamente, el secreto del voto posee también la función segunda de impedir estas formas de intimidación). Pero, además, los cabildantes en su comunicación a Castelli toman por «escandoloso hecho con el qe. [Campo Blanco] manifiesta de plano el odio qe. mantiene al Govno». Es decir, también el mero acto de votar en blanco constituye un "escándalo»; ello demuestra que lejos estamos todavía en estas primeras votaciones de algo que se asemeje a la aceptación de la libre opinión...

Pero sigamos un poco más a Castelli en su periplo altoperuano. En otra carta, fechada también el 10 de febrero de 1811, el enviado porteño informa a la Junta de Buenos Aires los primeros datos sobre la votación en la ciudad de La Paz: se había votado a un eclesiástico y Castelli indica a los paceños que deberán elegir a un «Yndividuo secular» ${ }^{62}$; la elección se vuelve a efectuar y el 4 de mayo, desde La Paz, el enviado de Buenos Aires señala que hubo «mas de quinientos sufragantes» en un nuevo acto eleccionario (es el tercero que se realiza en esa ciudad) lo que puede darnos un buena idea de cómo los niveles de participación están creciendo a ojos vista en estas primeras elecciones ${ }^{63}$.

Asi mismo, es interesante en función del problema de la representación que estamos analizando, el proyecto de Castelli para que la votación incluya también a los indígenas. En una proclama fechada en Charcas el 13 de febrero de ese año ${ }^{64}$, dirigida «a todos los habitantes del Distrito de la Real Audiencia de Charcas y muy particularmente a los Yndios», se acuerda «que sin perjuicio de los Diputados que deven elegirse en todas las ciudades y villas se elixa en cada una de las quatro Yntendencias del Distrito de esta Chancilleria ${ }^{65} . .$. un Representante de los Yndios que siendo de su misma calidad y nombrado por ellos mismos concurra al congreso con igual caracter y Representacion que los demas diputados»». El llamado a elecciones debía hacerse en las tres lenguas (castellano, qeshwa y aymará) y el sistema, bastante complejo, era doblemente indirecto; un cuerpo electoral primario amplio ${ }^{66}$ elegía tres electores por cada juzgado pedáneo, después éstos votaban los tres «segundos eligentes» en una asamblea electoral reunida en la

62 Charcas 10/1/1811, en AGN-X-3-10-2.

63 AGN- X-3-10-2.

${ }^{64}$ Incluída en una comunicación a la Junta del 1/3/1811; se le responde, el 26 de ese mismo mes, que «a la mayor brevedad se pongan en marcha los diputados Yndios», ambas en AGN- X-3-10-2.

${ }^{65} \mathrm{La}$ Paz, Potosí, Cochabamba y Charcas; también se las llamaba «provincias».

${ }^{66}$ El cuerpo electoral estaba compuesto de los «Casiques, Curacas Governadores, Alcaldes, Capitanes entregadores, Ayuntamiento y particulares», es decir, al parecer, todos los varones mayores de edad. Este complejo sistema indirecto se asemeja bastante el que se instauraría en Cádiz para los ayuntamientos constitucionales, consultar la circular del 7/1/1810, en Mayo Doc, tomo XI, pp. 14-29; para ver funcionar este sistema en un caso concreto, cf. Antonio ANNINO, «Cádiz y la revolución territorial de los pueblos mexicanos 1812-1821», Historia de las elecciones [1], pp. 177-226. 
cabecera del partido, quienes, una vez congregados en la capital provincial, votarían por un diputado como representante de la provincia. Este complicado operativo no dió aparentemente muchos resultados concretos; el 20 de mayo Castelli informa a Buenos Aires que ha vuelto a circular la orden en forma «executiva» ${ }^{67}$, pero, un mes después, la derrota de Huaqui acaba con estas ilusiones...

\section{LA ABORTADAS «JUNTAS PROVINCIALES»}

En medio de los preparativos, siempre en stand by, del congreso «nacional», la Junta Grande decide ampliar de algún modos sus bases de sustentación popular. Para ello, en febrero de 1811 dicta la resolución de creación de las «juntas provinciales» ${ }^{68}$. Afirmando que «la Junta siempre ha estado persuadida que el mejor fruto... debía consistir en hacer gustar a los pueblos las ventajas de un gobierno popular» y por lo tanto, serían «los pueblos» mismos quienes eligirían los nuevos órganos de gobierno local, así tendrían «los elejidos a su favor la opinión pública». De tal forma, en cada provincia (entiéndase aqui intendencia) se elegirían juntas cuyo presidente sería el gobernador intendente y que estarían integradas por cuatro vocales que «se eligiesen por el pueblo». Es interesante deternerse un poco en la forma de elección de estos vocales, pues es la primera vez que nos encontramos con instrucciones concretas en búsqueda de un cuerpo electoral más amplio que el de los «cabildos abiertos» analizados hasta ahora (aún tomando en cuenta los modos diversos en que éstos funcionaron en la realidad). Según Levene, este reglamento fue redactado por el dean Funes. No olvida, por supuesto, Levene hablar de «sufragio universal»o "práctica democrática» ${ }^{69}$ para referirse a este sistema electoral, fenómeno que, a todas luces, está aqui totalmente ausente, como se verá en los ejemplos que analizaremos más abajo.

El gobernador intendente o el cabildo, por medio de los alcaldes de barrio, citará a «los vecinos españoles de sus respectivos cuarteles a una hora señalada» para que «concurran todos a prestar libremente su voto para el nombramiento de un elector». Este elector deberá a su vez elegir «los colegas que hayan de componer la Junta». Es decir, estamos ante un cuerpo electoral amplio, si bien limitado a los «vecinos españoles» (veremos seguidamente que ello en realidad implica

67 AGN- X-3-10-2.

68 Buenos Aires, 10/2/1811, en RORA, tomo I, pp. 102-103. Uno de los escasos trabajos que existe sobre estas Juntas es el de Ricardo LEVEnE Historia de la Nación Argentina, dirigida por Ricardo LEVENE, «Las Juntas Provinciales creadas por el reglamento del 10 de febrero de 1811 y los orígenes del federalismo», volúmen V, segunda sección, Buenos Aires, Academia Nacional de la Historia, 1940, pp. 471-496. También en los dos capítulos siguientes del mismo volumen «El 5 y 6 de abril y sus consecuencias nacionales» y «Formación del Triunvirato», debidos así mismo a la pluma de Levene, hay información dispersa sobre este tema.

69 R. Levene [68], «Las Juntas Provinciales...», p. 479. 
un cierto desbordamiento de la concepción tradicional de vecindad imperante en el periodo colonial); un sistema de votación indirecta, utilizando los cuarteles urbanos como circunscripciones electorales primarias (donde no los hubiera, se harían seis subdivisiones a los mismos efectos). Y para que no hubiera dudas acerca de cuáles son los «electores ideales» en los que la Junta Grande está pensando, el artículo 21 indica taxativamente «deberán concurrir al nombramiento de electores, todos los individuos del pueblo sin escepcion de empleados y ni aun de los cabildos eclesiasticos y seculares, pues los individuos que constituyen estos cuerpos deberan asistir a sus respectivos cuarteles en calidad de simples ciudadanos al indicado nombramiento». El subrayado es nuestro e indica muy bien de qué modo aparece aquí en forma clara y concisa la distinción entre cuerpos e individuos, entre cuerpos electores, como el cabildo - e incluso el «cabildo abierto»- y ciudadanos individuales. Ahora no hay dudas: fuese cual fuese en el futuro la composición social y la extensión numérica ciertamente variable de la asambleas electorales, ellas estarán compuestas exclusivamente de individuos / ciudadanos. Han transcurrido ocho meses desde el coup d'état del 25 de mayo y hemos dado ya algunos pasos en ese sinuoso camino en búsqueda del individuo, ese personaje en el que se encarnaría idealmente el nuevo orden representativo.

Otro aspecto interesante es señalar la prohibición de elegir «eclesiásticos seculares o regulares, considerándose en ellos el mismo impedimento con que la antigua Constitucion los ha separado de los cargos concejiles en los Cabildos» ${ }^{70}$. Esta limitación va a dar lugar a un encendido alegato en favor de los esclesiásticos como ciudadanos, realizadas por un «Patriota Imparcial», en una carta a la Junta del 14 de febrero de 1811, es decir, cuatro días después de promulgadas las disposiciones sobre las elecciones para las juntas provinciales. Este notable documento recuerda que «todos los Ciudadanos y habitantes formamos un cuerpo social capaz de constituir un verdadero Estado o Nación» y que todos «sus miembros tienen unos mismos dros.» Y refiriéndose a las disposiciones de las leyes castellanas acerca de la prohibición de elegir a estos individuos para los oficios concejiles, no olvida señalar que «esta roto el vinculo de esas Leyes arbitrarias». Recuerda además el «Patriota Imparcial» que «en los Pueblos interiores los Eclesiasticos son regularmente. los mas ilustrados; asi vemos que estan eligiendo clérigos a pesar de qe. se previno al Vocal qe. existe en aquellas Provincias impidiese semejantes elecciones $\rangle^{71}$, aludiendo probablemente a Castelli (quien, como ya vimos, actuaría unos días antes en ese sentido en la elección paceña de diputados). Dada la importancia que los eclesiásticos tenían como intelectuales y como difusores de las ideas revolucionarias $^{72}$, ésta era, efectivamente, una limitación legal dificil de entender.

70 Artículo 19 de la disposición de creación de las juntas provinciales, en RORA, tomo I, p. 103.

71 Buenos Aires, 14/2/1811, en AGN-X-3-4-1.

72 Consultar nuestro estudio «Los primeros senderos de la revolución: la opinión en los balbuceos de la independencia rioplatense (1806-1813)», Izaskun ÁLVAREZ CUARTERO y Julio SÁNCHEZ GómEZ [12] y Roberto Di STEFANO, «Pastores de rústicos rebaños. Cura de almas y mundo rural en 
Algunos de los procesos electorales que dieron lugar a la elección de los vocales de las Juntas Provinciales, merecen que nos detengamos un momento en estas elecciones. En el caso de Cochabamba, los datos que poseemos revelan aspectos que son ciertamente de interés. El 16 de marzo de 1811 comienzan los preparativos de la elección - Cochabamba era una de las primeras ciudades altoperuanas que había dado muestras de su intención independentista-y desde el 4 de abril se inician las elecciones en ocho cuarteles de la ciudad ${ }^{73}$. Podemos seguir la elección cuartel por cuartel. En dos de los cuarteles la votación es secreta; en efecto, en el primer cuartel se dice «se pasó a efectuar esta [la elección] por los concurrentes en votación secreta» y en cuartel sexto se nos informa que "para que la botación se haga con mayor livertad escriva cada uno su voto en un papelito y lo deposite en la copa de un sombrero». En ambos casos, hay varios candidatos votados (cinco en el cuartel primero y seis en el sexto). También en los demas cuarteles, hay distintas formas de realizar la elección: en cuatro de ellos, si bien el voto es oral, hay evidentemente varios condidatos. Solo en los cuarteles segundo y octavo, la decisión se toma por consenso. En total votaron 188 individuos, poquísimo en relación a una ciudad que debería superar los 25.000 habitantes en ese entonces ${ }^{74}$, pero, si bien seguimos en este ámbito tan restringido de los vecinos notables, observamos que los distintos matices expresan diferencias evidentes en la concepción imperante acerca de cómo se debía expresar este reducido cuerpo electoral.

En el caso de Jujuy, votaron mas de 108 individuos $^{75}$ en los seis cuarteles en que se había dividido la ciudad (recuérdese que habian votado 75 en la elección de diputado de 1810); mas los apellidos de los votantes, en donde los nombres perteneciente a los linajes de la elite son numerosos - del Portal, Goycochea, Gorriti, Zegada, de la Quintana, etc. - nos muestran que poco hemos salido todavía de los círculos más estrechos de la notabilidad local.

Pero, este proceso eleccionario de las Juntas Provinciales termina mal. En algunos casos, las elecciones dieron como resultado un incremento de las rencillas entre los miembros de la reducida elite local. En el caso de San Juan, una comunicación de la Junta Grande de febrero de 1811, nos informa acerca del «espiritu de partido de qe. tanto abunda aquell bullicioso pueblo» y se decide nombrar al minis-

la cultura ilustrada riopatense», Boletín del Instituto de Historia Argentina y Americana «Dr. Emilio Ravignani», 3a. serie, 22, Buenos Aires, 2001.

73 Ver los documentos sobre la eleccción de la Junta Provincial de Cochabamba, en Asambleas Constituyentes Argentinas, [en adelante $A C A$ ], editadas por Emilio RAVIGNANI, Buenos Aires, Instituto de Investigaciones Históricas, Facultad de Filosofía y Letras, Peuser, tomo sexto, segunda parte, 1939 , pp. 5-14.

74 El Cercado, es decir, la ciudad y sus alrededores, tenía 22.305 habitantes en 1788, cf. Broke Larson, Colonialism and Agrarian Transformation in Bolivia, Cochabamba, 1550-1900, Princeton, Princeton University Press, 1988, p. 175.

75 Ver $A C A$, tomo VI, segunda parte, pp. 21-25; el número exacto es discutible tal como lo presenta la documentación publicada y puede haber una diferencia de dos votantes. 
tro contador de las Cajas Reales de Mendoza, Clemente Vanegas, para que «interviniera en el nombramiento de electores» en San Juan ${ }^{76}$. Probablemente, este «espiritu de partido» tenga que ver con una amplitud social del cuerpo electoral que ya hemos tenido ocasión de señalar para las ciudades de Cuyo ${ }^{77}$. En otros casos, se trata justamente de conflictos alrededor del problema de la extensión social de ese cuerpo electoral. En San Miguel del Tucumán, por ejemplo, el ayudante mayor don José Thomás de Alurralde trató de «Mulatos a varios vecinos honrrados tenidos y respetados por Españoles», en el medio de la asamblea electoral de uno de los seis cuarteles de la ciudad, interrumpiendo, afirma la fuente, «este respetuoso y circunspecto congreso» ${ }^{78}$. Y podríamos seguir con otros ejemplos ${ }^{79}$. Este proceso eleccionario dio impulso a una dinámica de contienda entre grupos de la elite $-\mathrm{y}$ en ciertos casos, con la intervención de nuevos actores sociales - que abría insospechados y dificiles caminos. Pese a ser consciente de la necesidad de contar con esas Juntas Provinciales como formas de extensión de la representación ${ }^{80}$, en febrero de 1812, el primer Triunvirato (que ha sucedido en septiembre de 1811 a la Junta Grande como titular del poder ejecutivo) ante una realidad cada vez más conflictiva y frente al proceso de crecimiento evidente de la autonomía local que estas Juntas impulsaban, situaciones que a todas luces se le escapaban de las manos, decide acabar con este experimento ${ }^{81}$.

\section{LA FALLIDA ASAMBLEA DE ABRIL DE 1812}

Mientras se desarrollaba este proceso, finalmente interrumpido, de las Juntas Provinciales, la idea de llamar a una asamblea o «congreso nacional», seguía en

76 Buenos Aires, 16/2/1811, en AGN-X-3-4-1.

77 La situación de San Juan era ya conflictiva desde unos meses antes, ver los documentos de noviembre de 1810, en AGN-X-3-1-11.

78 Ver $A C A$, tomo VI, segunda parte, pp. 14-20, las citas en p. 19.

79 Por ejemplo, en una comunicación a la Junta subalterna de Jujuy, la Junta Grande señala que «Quando este super. Govno. Decretó la ereccion de Juntas en las ciudades, nada menos quiso qe. multiplicar autoridades cuyas competencias ocasionasen division y ruina de los Pueblos», refiriéndose a un reciente conflicto interno en esa ciudad; Buenos Aires, 9/4/1811, en AGN-X-3-4-1. LEVENE menciona también otros conflictos en «Las Juntas Provinciales...», [68].

${ }^{80}$ Un largo folleto, sin título, que comienza «El primer movimiento con que la capital de Buenos Ayres hizo ver sus derechos...», publicado en Buenos Aires en agosto de 1811, en el que se informa acerca de la misión de Saavedra y Manuel Felipe Molina hacia el Alto Perú, hace repetidamente hincapié en estas formas institucionales; un ejemplar del folleto en la colección Carranza de la Biblioteca Nacional de Buenos Aires.

81 Ver $A C A$, tomo VI, segunda parte, pp. 44-45. Levene glosa, sin comentarios, una frase de ese documento que habla de «la eroica resolucion tomada de concentrar el poder», "Las Juntas Provinciales...», [68], p. 495. Se trataba, en efecto, de concentrar el poder, pero no estoy seguro que el autocalificativo de «eroico» sea el más adecuado para entender esa decisión. 
pie. En febrero de 1811, la Junta Grande envía a todas las ciudades cabeceras una comunicación en los términos siguientes:

«Siendo tan importante al bien de todas las Provincias ${ }^{82}$ de nuestra comprehension, la breve incorporacion de Diputados en este gobierno para organizar quanto antes el augusto Congreso Nacional que debe representarlas, es muy digno del zelo y patriotismo de V.S. que proceda con la mayor eficacia en el distrito de su jurisdiccion a promover el nombramto. de los Diputados que aun no se hallan elegidos... pa.qe. asi estos como los q. ya lo estén se presenten a la mayor brevedad en esta Capl. .... $\rangle^{83}$

Menos de un mes más tarde, el 24 de marzo, la Junta escribe al Cabildo porteño, señalándole que dado que «han cesado ya las aguas en las Provas. de Arriba unico impedimento qe. ha retardado hasta ahora la llegada de los Diputados de sus Pueblos, cree la Junta qe. es llegado el caso de qe. en esta Capital se proceda al nombramto. de dos Diputados de ella». Agrega después «Como pa. semejante deciciones sea indispensablemte. necesario qe. cada ciudadano tenga una parte activa en ellas en qe. exprese su libre voluntad», la Junta piensa que la mejor forma de hacer esta elección es guiarse por el método ya preparado para las Juntas Provinciales, con la diferencia que, en vez de nombrar un elector por cuartel, se lo elija por cada manzana de la ciudad. De este modo cada «ciudadano de por si pueda con satisfaccion decir qe. ha nombrado sus Diputados ${ }^{84}$. En julio de 1811, se discute en el cabildo porteño la formación de una lista «de mil individuos de los que se consideren idoneos para elegir» los diputados ${ }^{85}$. De hecho, en agosto el cabildo manda imprimir las esquelas para acudir a la «elección de Diputados de esta Capital para el congreso nacional de estas Provincias» y establece que «la eleccion debe hacerse por villetes secretos, expresando el nombre y apellido del Diputado, debiendo cada elector presentar la esquela con su voto» ${ }^{86}$. Las esquelas son nominales; ello muestra en forma evidente que están dirigidas a la formación de un cuepo electoral restringido y corresponden a todas luces a las listas que el cabildo tiene ya prontas el 9 de agosto,

82 Muchos documentos de este periodo dicen «Provincias», pero, no está demás recordar que éstas no tienen ninguna relación con las que nacerían a partir de 1820 , se trata aqui de los territorios de las ciudades cabeceras de intendencia —en general, al hablar del Alto Perú, se hace referencia a esa circunscripción administrativa- o de los de las llamadas «ciudades principales», noción bastante laxa. Leer este apelativo a partir de las divisiones político administrativas posteriores a 1820 sería algo completamente anacrónico. Sobre la historicidad del término, ver GuERRA [2], Modernidad e independencias y José Carlos ChIARAMONTE, «El federalismo argentino en la primera mitad del siglo XIX», Marcello CARMAgnani, (coord.), Federalismos latinoamericanos, México/Brasil/Argentina, México, FCE, 1993.

83 Buenos Aires, 27/2/1811, en AGN-X-3-4-2.

${ }^{84}$ Buenos Aires, 24/3/1811, en AGN-X-3-4-1.

85 Acuerdos del Extinguido Cabildo de Buenos Aires, publicados por Augusto E. Mallié, [en adelante $A C U B A$ ], serie IV, tomo IV, Buenos Aires, 1927, p. 513, acuerdo del 31/7/1811.

86 Documento sin fecha, pero su datación más probable es agosto de 1811 y ha sido publicado en RMAIE, tomo II, pp. 459-460. 
pero el gobierno previene «se suspendiese el repartimiento de esquelas hasta que avisase ${ }^{87}$. Las idas y venidas entre el cabildo y la junta son incesantes en esos agitados días. $\mathrm{Y}$ es indispensable ahora retrotraerse unos meses atrás.

En efecto, los agitados acontecimientos de la política porteña de esos meses complicaron rápidamente la cuestión del congreso. Juan Cánter ha estudiado en detalles este momento tan particular, en medio de los conflictos entre las más diversas facciones porteñas ${ }^{88}$ y no entraremos aqui en detalles, solamente nos centraremos en el tema de la representación. Mas, de todos modos, es indispensable hacer un muy breve resumen. Los hechos del 5 y 6 de abril, presentados como una «revancha» de Saavedra, dieron un golpe al sector más cercano a las ideas de Moreno, pero no acabaron con él. Gorriti en sus escritos autobiográficos señala claramente la autoría de Saavedra y del dean Funes en los acontecimientos de abril ${ }^{89}$.

El carácter tan peculiar de los hechos del 5 y 6 de abril, merece que hagamos un breve paréntesis. Aparecen aqui hombres «nuevos» y ajenos completamente a la élite tradicional porteña, tal el caso de Campana y otros como el alcalde de las quintas, Thomas Grigera, capitaneando un grupo nutrido de individuos - llamados por Núñez «hombres de poncho y chiripá» ${ }^{90}$, para que no tengamos dudas acerca de su proveniencia rural. Beruti los llama «gente campestre» ${ }^{91}$. Vicente Fidel López se refiere a ellos como «gentes colecticias ${ }^{92}$ de las clases que habitaban en los subúrvios»; multitud que se congregaba «sin conciencia propia de lo que hacía», agrega después. Levene no duda en afirmar que se enfrentaron en esta ocasión «la parte culta de la sociedad o el centro y la [...] plebe o el populacho del suburbio, las quintas y la campaña» ${ }^{93}$. Alberto Palcos habla de los «emponchados de los suburbios» y de las «masas ignaras» ${ }^{94}$. La descripción que realiza López sobre el princi-

${ }^{87} A C U B A$, serie IV, tomo IV, p. 518, acuerdo del 9/8/1811 y p. 525, acuerdo del 16/8/1811.

88 Juan CÁNTER, «El año XII, la asambleas generales y la revolución del 8 de octubre», [68], vol. V, pp. 587-756.

89 Ver «Autobiografía política», ed. cit., pp. 28-29. Gorriti menciona a una tercera persona «cuyo nombre callo por el decoro de su familia» y que probablemente se trate del diputado Manuel Felipe de Molina.

90 «Se apeló a los hombres de poncho y chiripá contra los hombres de capa y de casaca» Ignacio NúÑEZ, Noticias históricas de la República Argentina, [1857], Buenos Aires, edición de la Biblioteca de Mayo. Colección de Obras y Documentos para la Historia Argentina, tomo I, Memorias, Edición especial en homenaje al $150^{\circ}$ aniversario de la Revolución de Mayo de 1810, 1960, p. 452. Un análisis más extenso de estos hechos en Gabriel Di MeGLIO, La participación política de la plebe urbana de Buenos Aires en la década de la revolución (1810-1820), Tésis de licenciatura, Fac. de Filosofía y Letras, UBA, Buenos Aires, 2000, pp. 48-58.

91 Juan Manuel Beruti, Memorias curiosas, Buenos Aires, Emecé, 2000, p. 164

92 Colecticio: según el Diccionario de la Academia «Aplícase al cuerpo de tropa compuesto de gente nueva, sin disciplina y recogida de diferentes lugares»

93 Ricardo LEVENE, «El 5 y 6 de abril y sus consecuencias nacionales», [68], Vol. V, pp. 497537, la cita es de la página 530.

94 Alberto Palcos, Rivadavia. Ejecutor del pensamiento de mayo, La Plata, Biblioteca de Humanidades, Facultad de Humanidades y Ciencias de la Educación, 1960, vol. I, pp. 130-132. 
pal dirigente de esa extraña multitud es concisa y transparente: «Grigera era una vecino afincado y aunque campesino inocente y refractario, ejercia en todo el rústico vecindario de su pago, una especie de patriarcado bondadoso y respetable... Tenía la figura caracteristica de los hombres de las orillas. Su modo de hablar y sus conceptos, siempre graves y sentenciosos, revelaban el hábito que habia contraido de resolver las contiendas de sus convecinos con máximas de moral y de buena ley, según él lo entendía». Sobre los Campana, la evocación de López es también interesante «Vecino al Alcalde de las Quintas, habia vivido por siglo y medio, en una granja o chácara estensa y solitaria pero de pingües frutos, una familia honorable, establecida alli por uno de los más antiguos agricultores del tiempo colonial» ${ }^{95}$.

Hablemos un poco de este Thomás Grigera ${ }^{96}$, miembro de una extensa familia de campesinos labradores, ubicados primero en San José de Flores ${ }^{97}$ y más tarde, en las Lomas de Zamora, perteneciente entonces al partido de Quilmes. Poseían los Grigera varias explotaciones agricolas que formaban parte del extenso cinturón de quintas, elemento esencial para el abasto de la ciudad en frutas, verduras y sobre todo, forraje - el combustible indispensable para el transporte de hombres y mercancías en aquellos tiempos. No sabemos si, como dice López, era don Thomás un «campesino inocente y refractario»; sólo podemos mencionar que actuó decididamente en varios conflictos del periodo, como el que opuso a saladeristas y abastecedores en 1817; allí Grigera aparece firmando contra los dueños de los saladeros, al lado de personas relevantes como Antonio Millán, otro conocido vecino de San José de Flores y pequeño estanciero en Cañuelas. Este escrito, cuyos autores se llaman a sí mismos «Labradores, Hacendados, Reseros, abastecedores y Artesanos... $\rangle^{98}$, fue uno de los tantos que agitaron la ciudad en ese polémico enfrentamiento (Adolfo Saldías publicó en su momento otros documentos referidos al tema ${ }^{99}$ ). Pero sobre todo, si este hombre era «inocente», no parecía falto de cultura y de inquietudes, pues es el autor de unos de los raros tratados de agricultura dados a imprenta en América hispana en aquellos años, el Manual de Agricultura publicado en Buenos Aires en 1819100. En el proemio de su obra, dice de sí mismo «el americano Tomas Grigera, labrador en los suburbios de la Capital de las Provincias Unidas» y afirma en el prólogo al

95 Historia de la República Argentina..., Buenos Aires, Casavalle, tomo III, 1883, pp. 461463. [los subrayados son de López].

96 Fue Alcalde de Barrio «principal» y tuvo como función en mayo de 1811, proponer al cabildo los nombres de los restantes Alcaldes de Barrio de la quintas aledañas del ejido, AGN-X-3-4-1.

${ }^{97}$ En 1813, uno de los tenientes de alcaldes de Flores es Mariano Grigera y la lista de vecinos de prestigio está encabezada por Thomás Grigera y Manuel Antonio Grigera, AGN-X-3-8-8.

98 Ver AGN-IX-10-3-3.

99 Adolfo Saldías, Historia de la Confederación Argentina, tomo I, Rozas y sus campañas, Buenos Aires, Orientación Cultural Editores, 1958, pp. 28-31.

100 Imprenta de la Independencia, Buenos Ayres. Señalemos para aquellos que no conozcan el texto de Grigera, que es éste un manual práctico en donde desfilan el trigo, la cebada o las coles y no se trata en absoluto de una reflexión «filosófica» sobre la agricultura. 
lector «El imperio de la razon es el único que debe arredrar al hombre», para agregar más adelante «Mucho hay escrito por plumas cortadas con finura y llevadas por principios que no podré explicar. Comunico solamente a mis conciudadanos, que educados en mejor tiempo que yo, corren en post de las ventajas y de la gratitud del cultivo de las tierras, lo que en el constante trabajo de esa madre comun de los vivientes he aprendido» ${ }^{101}$. Como se puede apreciar, no se trata de un «intelectual», pero sí de alguien que parecía estar en inmejorables condiciones para expresar bien el sentir de sus compaisanos en el marco de la vida rural de ese área tan peculiar que constituían las «orillas» de la ciudad ${ }^{102}$.

Y justamente, son esos los individuos que se hallan en esa jornada. Detengámonos un poco en la descripción que hace Núñez de los acontecimientos: «al anochecer del día 5 de abril empezaron a reunirse hombres emponchados y a caballo en los mataderos de Miserere ${ }^{103}$ a la voz del alcalde de barrio don Tomás Grigera... y antes de venir el día ocuparon la plaza Mayor como mil quinientos hombres, pidiendo a gritos la reunión del cuerpo municipal, para elevar por su conducto sus reclamaciones al gobierno [...] A las dos de la mañana del día 6 se presentó a la Municipalidad el alcalde Grigera con las peticiones del pueblo... ella contenía diecisiete peticiones, cada una de las cuales principiaba de este modo -El pueblo pide» ${ }^{104}$. No podemos extendernos mucho aqui en los detalles de esas peticiones - que expresaban sobre todo, las exigencias del grupo cercano a Saavedra contra los antiguos «morenistas»— sólo nos interesa señalar que esta irrupción de los hombres de «poncho y chiripá», si bien es la primera, como es público y notorio, no sería la última. De todos modos, rescatemos un aspecto de la representación: el resquemor creciente contra los españoles europeos y contra todos los que no sean «naturales del pais» ${ }^{105}$. Además, el documento está firmado para la mayor parte de los alcaldes de barrio y sus tenientes de alcaldes ${ }^{106}$. Esta organización administrativa y policial, nacida a fines del periodo colonial en la ciudad, con alcaldes por cuartel y tenientes por cada manzana, había sido ideada como una forma de ordenar la «policía» urbana en el sentido más amplio (limpieza, abasto, orden, control, etc.) y pronto se agregarían a sus deberes las obligaciones derivadas del servicio militar en las milicias cívicas urbanas. En las

101 Manual de Agricultura, Buenos Aires, 1819, pp. V-VI.

$102 \mathrm{Cf}$. Valeria CiLIBERTO, Entre la campagne et la ville: aspects socio-démographiques de la croissance suburbaine. Flores, 1815-1869, Mémoire de DEA, EHESS, Paris, 1988.

${ }^{103}$ Que Grigera tenía buenas relaciones con los abastecedores y corraleros lo demuestra su actuación posterior en 1817 en el ya mencionado conflicto con los saladeristas.

104 Ciliberto, [102], pp. 453-457.

${ }_{105} \mathrm{Y}$ esto no sólo se relaciona con la actitud frente a la experiencia revolucionaria. Ya en ese entonces, la situación desigual de naturales y «extranjeros» frente al servicio de las armas, comienza a ser también un motivo de discordia entre unos y otros; un escrito de un oficial de milicias urbanas de 1812 habla de los «justos clamores de mis soldados americanos sobre la desiguadad con qe. se compele solo a éllos a serbir a las armas y no a los europeos», Alejo Matoso, Buenos Aires, 8/6/1812, en AGN-X-6-6-4.

106 Ver la lista completa en $A C U B A$, serie IV, tomo IV, pp. 450-452. 
quintas, el propio Grigera, como ya vimos, había sido el artífice de su nombramiento. Estos individuos han tejido obviamente una extensa red de solidaridades y no nos extrañaría (conociendo algunos nombres como los de Celestino Salguero de San Isidro, los Valenzuela de San José de Flores y otros, como los de Bejarano, Moraña, Portela, etc.) que nos hallásemos con un mundo de pequeños propietarios de quintas y chacras y de artesanos urbanos - sobre más de un centener de nombres, hay sólo diez «don». Un espectro social similar para estos auxiliares de la justicia de paz al que veremos en los años 1830/1850 y que ha sido ya estudiado para el caso de la campaña y también, para las áreas más próximas al ejido ciudadano ${ }^{107}$.

Este hecho está ya mostrando cambios profundos en las formas de representación en la ciudad y en los sectores sociales concernidos. Desde ahora, será cada vez más difícil para los hombres de la ciudad no tomar en cuenta los intereses y reclamos de esos sectores rurales, ajenos hasta ese momento a las conmociones de la política porteña. De este modo, el campo de la representación se amplia, mas no lo hace sólo — ni necesariamente_ a través de mecanismos electorales.

Pero retomemos el hilo de los acontecimientos. La derrota de Huaqui del 20 de julio de 1811 , le dió aire nuevamente al grupo político desplazado en abril, que lentamente vuelve a pesar en las rencillas cercanas al poder en Buenos Aires. Se llega así al momento clave en septiembre de ese mismo año, cuando los responsables del golpe del 5 y 6 de abril serán derrotados ${ }^{108}$, en parte gracias a la acción del cabildo y el primer Triunvirato asume el poder ejecutivo. Esta nueva conformación triunviral del ejecutivo es un resultado de la elección de diputados (y de miembros de una comisión «consultora del Gobierno») realizada el 19 de septiembre. Esa elección, con un cuerpo electoral más amplio que el de los anteriores cabildos abiertos porteños, pero siempre dentro del marco restringido de los «vecinos» notables $^{109}$, se efectuó en forma oral e individual («los votantes devian entrar en la Sala uno por uno à prestar su sufragio» ${ }^{110}$ ) y dió los resultados siguientes:

107 Ver nuestro trabajo «Paz, orden y trabajo en la campaña: la justicia rural y los juzgados de paz en Buenos Aires, 1830-1852», Desarrollo Económico, vol. 37 (146), pp. 241-262, Buenos Aires, julio- septiembre, 1997, ahora en GARAVAGLIA [61], pp. 57-87. También, la tésis en curso de Valeria Ciliberto sobre los alrededores de Buenos Aires en el siglo XIX.

108 Saavedra, Manuel Molina y Funes se hallan en ese momento ausentes de Buenos Aires. Los dos primeros se hallan en Tucumán y el deán Funes en la Banda Oriental.

109 Cánter afirma que hubo en esta ocasión intentos, fallidos, de ampliar el cuerpo electoral, cf. CÁNTER, [88], «El año XII, la asambleas generales y la revolución del 8 de octubre», p. 601. De todos modos, Beruti señala que se pusieron tropas en la plaza Mayor «obviando ... el que no entrasen negros, ni muchachos ni otra gente común», BERUTI, [91], p. 181.

$110 A C U B A$, serie IV, tomo IV, p. 560. 
CUADRO 2: Elección de diputados y «consultores» en el cabildo porteño del 19 de septiembre de 1811

\begin{tabular}{|l|c|}
\hline CANDIDATOS & VOTOS \\
\hline Feliciano Antonio Chiclana & 783 \\
\hline Juan José Paso & 743 \\
\hline Manuel de Sarratea & 616 \\
\hline Marcos Salcedo & 546 \\
\hline Fray Igancio Grela & 545 \\
\hline Martín de Arandia & 536 \\
\hline Francisco Ugarteche & 535 \\
\hline Juan José de Anchorena & 532 \\
\hline Fray Francisco Castañeda & 463 \\
\hline Tomás de Rocamora & 432 \\
\hline Esteban Romero & 413 \\
\hline José León Planchon & 383 \\
\hline Bernardino Rivadavia & 360 \\
\hline Victoriano la Fuente & 306 \\
\hline Fray Nicolás Herrera & 225 \\
\hline Antonio Sáenz & 209 \\
\hline José Joaquín Ruíz & 163 \\
\hline Vicente López & 161 \\
\hline
\end{tabular}

Como se puede apreciar, ni siquiera en la propia ciudad de Buenos Aires, Rivadavia parece ser uno de los tribunos más populares, pues su nombre aparece bien abajo en la lista de los vecinos destacados en el ámbito estricto de la notabilidad porteña. Días más tarde, un encuentro posterior entre la oposición y la Junta instituye el primer Triunvirato acudiendo a los tres hombres más votados el 19 de septiembre ${ }^{111}$.

La Junta, ahora con el nombre de «Junta Conservadora ${ }^{112}$, queda en funciones vagamente legislativas y el choque entre ella y el Triunvirato no se hizo esperar. El 7 de noviembre, el Triunvirato la disuelve (y envía a su casa a los diputa-

111 CÁNTER, [88], «El año XII, la asambleas generales y la revolución del 8 de octubre», pp. 611-613.

112 Su título completo era Junta «Conservadora de la soberanía del Sr. D. Fernando VII y de las leyes nacionales», ver el «Reglamento» de septiembre de 1811, en $A C A$, tomo VI, segunda parte, p. 600. 
dos del interior). La razón era evidente: la Junta había dictado un «Reglamento» el 22 de octubre, pretendiendo seguir en el goce de la potestad legislativa. El Triunvirato, que no quería ya compartir el poder con ninguna institución (y menos, con los diputados de las «provincias») tuvo la idea genial de pasar este «Reglamento» al... cabildo de Buenos Aires para que éste diera su opinión. La Junta, obviamente, le señala que «la voluntad libre y espontanea de los pueblos que representamos, no puede suplirse, ni reformarse por el parecer de una sola corporacion dependiente, que ella misma he elegido sus diputados y les ha transmitido su poder. A mas de esto, si el Excmo. Cabildo de Buenos Ayres tiene derecho a ser consultado sobre el reglamento, no lo tiene menos los de nuestra representacion» ${ }^{113}$. El argumento de la Junta era institucionalmente irrefutable, pero el Triunvirato la disuelve por considerar «atentario» el «Reglamento»...

Se vuelve a hablar ahora de la convocatoria al Congreso. En efecto, en el artículo 1ro. del «Estatuto Provisional del Gobierno superior de las Provincias Unidas del Río de la Plata» ${ }^{14}$, dictado por el Triunvirato unos días más tarde, el 22 de noviembre de 1811, se menciona a la asamblea que se debería reunir y en el 3ro. se habla de «la apertura del congreso de las provincias unidas», una vez que las circunstancias lo permitieran. Esa asamblea tendría una conformación muy particular, pues estaría compuesta por el ayuntamiento de Buenos Aires, los representantes «de los pueblos» y por un «numero considerable de ciudadanos elegidos por el vecindario de esta capital». Como se observa, el «partido» porteño que había ganado finalmente la pulseada con los enviados del interior que integraban la Junta Grande, no tenía la menor intención de que el futuro congreso se le escapase de las manos; en efecto, ahora estarían incluídos en él, no sólo el cabildo y los diputados de las «provincias», sino también un «número considerable» de vecinos de Buenos Aires... El secretario del Triunvirato, Bernardino Rivadavia (según la mayoría los autores, el «alma» de esta nueva experiencia ${ }^{115}$ ) enviaba de este modo un diáfano mensaje que expresaba cuáles eran sus ideas acerca de la constitución de la nueva nación que se estaba creando.

Habría que esperar unos meses antes que, en enero de 1812, se activase nuevamente el llamado a la reunión del congreso. Los «desastres de la guerra» no permitían pensar en otra cosa que no fuera la realidad cotidiana de los enfrenta-

${ }^{113}$ Fue tan pública la disputa entre la Junta y el Triunvirato, que el nutrido intercambio de esquelas entre ambas instituciones fue objeto de un folleto de 12 páginas intitulado Documentos oficiales que publica la Junta Conservadora, Imprenta de Niños Expósitos, 1811. La cita es de las pp. 10-11 del citado folleto de la colección Carranza de la Biblioteca Nacional de Buenos Aires.

114 ACA, tomo VI, segunda parte, p. 604.

115 Ver Ricardo LEVENE, «Formación del Triunvirato», [68], vol. V, pp. 539-585; la expresión «alma del Triunvirato» es de este autor. Hasta un panegirista de Rivadavia como Alberto Palcos no puede evitar su incomodidad al referirse a estas medidas inspiradas por su biografiado, cf. PALCOS, [94] Rivadavia, vol. I, pp. 165-179. Rivadavia fue secretario de Guerra del Triunvirato y desde el 25 de marzo, también lo integró como miembro. 
mientos armados, sea en el norte —alli, la derrota de Huaqui había abierto el camino de los realistas hacia las provincias de «abajo»- como en la Banda Oriental, donde un poderoso ejército portugués campeaba ya en Maldonado. Por un tiempo, una parte sustancial de la polémica acerca de la representación va a estar centrada en el reducido espacio de la ciudad de Buenos Aires y, secundariamente, de su campaña. Pero volvamos a la circular del 17 de enero de 1812; en ella se anuncia a varias de las ciudades cabeceras del antiguo virreinato - las altoperuanas, ocupadas ahora por los realistas después de la derrota de Huaqui, están excluídas de este llamado. La circular ordena «procedan á hacer por si, y en union de 12 vecinos patriotas el nombramto. de sus representantes» ${ }^{116}$; primer hecho que debería ser señalado, ahora el cabildo y los doce «vecinos patriotas» forman un reducidísimo cuerpo electoral en las ciudades cabeceras. Pero, para que no queden dudas acerca de los objetivos apenas disimulados de esta circular, ella agrega que esos electores «deben elegirlos de Sugetos residtes. en esta Capl. para evitar demoras y costos». O sea, aquel reducido cuerpo electoral no tiene ni siquiera la libertad para elegir a su representante, pues debe hacerlo por algunos de los «Sugetos residtes. en esta Capl.» Cualquier comentario que se pueda hacer acerca de esta circular parece casi inútil; ella señala hasta qué punto, el estrecho círculo que estaba controlando ahora el proceso en la antigua capital virreinal quería evitar a toda costa la expresión de una voz discordante de la suya propia.

Para tener una idea de cómo se efectuaron estas elecciones de diputados en las ciudades del interior, tomemos el caso de Córdoba. El 13 de febrero de 1812 se reúnen en la sala consistorial cinco de los capitulares convocados por el gobernador intendente ${ }^{117}$. Los presentes eligen en ese acto a los doce «vecinos conocidamente Patriotas para que designen el Sugeto que deva concurrir a la Asamblea general que se ha de crear», citándoles para el día siguiente. De este modo, el 14 de febrero asisten a la reunión el gobernador intendente, diez capitulares y los doce vecinos designados para proceder a la elección. Detengámonos un momento en los dichos del alcalde de segundo voto, Manuel Felix Texada: «que en atencion à no tener conocimiento ninguno en el Capital e ignoraba la calidad de los individuos existentes en su territorio para formar juicio si son buenos o malos, adictos a nuestra causa ó enemigos de ella, se conforma segun derecho a la pluralidad de este Ilustre Cuerpo» y lo mismo, palabras más, palabras menos, dirán varios de los concurrentes a la reunión. Finalmente, ante las dudas planteadas, se decide dejar la decisión en manos del... cabildo de Buenos Aires. Este, en acuerdo del 17 de marzo, elige al clérigo Juan Andrés Aguirre, por ser «sugeto de notoria ilustracion, providad y adhesion al sistema de las Provincias

116 Gran parte de la documentación fue publicada por Emilio Ravignani en $A C A$, tomo VI, primera parte, Peuser, Buenos Aires, 1939; la circular en p. 629. Había sido ya parcialmente publicada en RORA, tomo I, pp. 139-162.

117 Todos los datos de esta elección en AGN-X-6-6-2.

R. I., 2004, n. $^{\circ} 231$ 
unidas à mas de ser oriundo de la misma Ciudad de Cordova ${ }^{118}$. Es decir, ni siquiera esta reducidísima asamblea de 22 vecinos consigue en Córdoba elegir un representante $\mathrm{y}$, finalmente, es el ayuntamiento porteño quien toma la decisión...

En Buenos Aires comienza ahora un complejo proceso de correspondencia entre el cabildo porteño y el Triunvirato, en función de cuales serían la normas para la elección de los representantes porteños para el congreso. El 19 de febrero, el poder ejecutivo dicta el «Reglamento que da forma a la Asamblea Provisional» ${ }^{119}$; los primeros dos artículos retoman las normas ya comentadas, pero especifican mejor la forma de elección de los cien ciudadanos de Buenos Aires que acompañarán a los miembros del cabildo porteño y a los enviados por los cabildos del interior. Se establece así, un complicado proceso indirecto. Buenos Aires se divide en cuatro secciones; en cada una de ellas un regidor — nombrado por el ayuntamiento - recibiría en «sus casas de cada vecino un cédula firmada y cerrada en la que manifiesten su voto a favor de dos ciudadanos de la misma seccion para que desempeñen el cargo de electores». Estas cédulas serán abiertas en el ayuntamiento y los dos electores por cada sección quedarían así electos. Reunidos los ocho elegidos de este modo «nombrarán con el Ayuntamiento trescientos ciudadanos cuyos nombres se escribirán en papeles separados, se echarán en un saco ${ }^{120}$ y serán miembros de la Asamblea los cien primeros que salgan a la suerte». Un complicado sistema, ideado sólo para filtrar al máximo toda expresión que pueda poner en peligro la preeminencia del ejecutivo triunviral (y para multiplicar el peso de la representación de los «vecinos» de la capital). El artículo 7 reafirma plenamente esto, con dos limitaciones adicionales: «Solo el Gobierno podrá convocar a la Asamblea»y ésta no podrá permanecer en sesiones por mas de «ocho días».

El activo intercambio de notas entre el cabildo porteño y el Triunvirato, acerca de los procedimientos electorales y las prerrogativas de la futura asamblea, se hace casi cotidiano en los días subsiguientes. Y es notable señalar que en casi todos los temas sometidos a discusión, el ayuntamiento parece estar mucho más atento a escuchar «la opinión de los pueblos» que el Triunvirato. Y por vez primera, en el acuerdo capitular del 2 de marzo, se mencionan en el proceso de insaculación de los ciudadanos —el cabildo propone que sean cien y no los trescientos del proyecto original, para después insacular treinta de ellos ${ }^{121}$ — a los «vecinos de esta Ciudad de la campaña ó de los demas Pueblos» ${ }^{122}$. Asi, aparecen ahora también como actores políticos los «vecinos de la campaña». Pensamos que esto no es más que una consecuencia de la activa presencia de los pobladores rurales durante los acontecimientos del 5 y 6 de abril. El cabildo, al con-

118 Este acuerdo fue publicado en $A C A$, tomo VI, primera parte, pp. 651-652.

119 Ibidem, pp. 631-633.

120 Para atenerse a la etimología estricta de la palabra insaculación [sacculus, $i=$ pequeño saco] se ha elegido en esta ocasión un saco como peculiar urna electoral.

121 Finalmente, se decide que sean 33 los ciudadanos insaculados de ese modo.

$122 A C A$, tomo VI, primera parte, p. 641 [subrayado nuestro]. 
trario de Rivadavia, había recibido una parte del mensaje expresado en aquella movilización de los hombres de «las orillas». El ayuntamiento capitalino, en los considerandos de esta propuesta, le recuerda al ejecutivo que «El objeto de toda eleccon. es establecer una buena representacon.» Y que «Sobre todo deven consultarse los dros. y representaciones de los demas Pueblos ${ }^{123}$. Todos son partes integrantes del Cuerpo Social» y pese a ser esa corporación una representante nata del reducido ámbito de los vecinos porteños, le da una pequeña lección al Triunvirato, señalándole que «deve desaparecer toda notable desigualdad sin embargo de la mayor importancia politica, qe. en todos respectos le da ala Capital su posicion». De todos modos, no nos engañemos, el cuerpo electoral porteño había sido claramente definido en el artículo 3 del «Reglamento» de noviembre de 1811, que especificaba quiénes no tenían derecho a ser electores ni podían ser electos y se menciona alli, entre otras causales más evidentes, la de «no tener arraigo o giro conocido» ${ }^{124}$ (es decir, todos aquellos que no constituían realmente «la parte más sana y principal» de la población, tal como decía el acta del 25 de mayo de 1810). El ayuntamiento procedería en los meses siguientes a realizar los «padrones» de ese cuerpo electoral de vecinos así definido y en el citado acuerdo del 7 de marzo, se vuelve a señalar la exigencia de atenerse estrictamente a ellos en el momento de la votación ${ }^{125}$.

El Triunvirato termina aceptando parte de las propuestas del cabildo y así, el 9 de marzo, se decide, en el artículo 2 de las adiciones al reglamento de la asamblea, que «Los vecinos dela Campaña conlas calidades requisitas, tienen derecho à ser electores y electos enla Asamblea, del mismo modo qe. los de esta Capital y demas Pueblos delas Provas. Unidas con tal que puedan asistir pa. el tiempo de la apertura ${ }^{126}$. De esta forma, queda por vez primera sancionada la legitimidad de la presencia de los habitantes de la campaña en el proceso de elección de representantes para las sucesivas asambleas. Pero de todos modos, en esta ocasión, los vecinos de la campaña no participaron realmente en la elección de los representantes de Buenos Aires, tal como surge de las listas electorales destinadas a elegir los vocales para la asamblea publicadas por Ravignani. En efecto, según estas votaciones, realizadas exclusivamente en las cuatro secciones electorales en que se había dividido la ciudad, votaron entre el 31 de marzo y el 3 de abril, 263 individuos en la primera sección ${ }^{127}, 236$ en la segunda, 231 en la tercera y 126 en la

${ }^{123}$ La expresión «los Pueblos» suele hacer referencia a los vecinos de las principales ciudades del interior; sobre la polisemia del término en la época, ver GUERRA [2], Modernidad e independencias, pp. 351-381.

124 ACA, tomo VI, primera parte, p. 631.

125 Ibidem, p. 645.

126 Según borrador en AGN-X-6-6-1, ligeramente distinto al publicado por Emilio Ravignani en $A C A$, tomo VI, primera parte, p. 647.

127 Una lista, diferente a la publicada por Ravignani, de esta primera sección, da una cifra superior de 265 votantes con el agregado de dos votantes al final — los dos hermanos Balbastro, Eu- 
cuarta $^{128}$. O sea un total de 856 electores para toda la ciudad; ella contaba en ese entonces alrededor de 45.000 habitantes. ¿Es poco o mucho? Veamos: ¿cuántas fueron las personas que participaron del cabildo abierto del 22 de mayo de 1810 ? A esa reunión fueron invitadas 450 personas y asistieron sólo 251 (los restantes o tenían buenas razones para no arriesgarse a asistir o fueron hábilmente filtrados en las entradas a la Plaza Mayor $\left.{ }^{129}\right)$. Es decir, hay de nuevo en esta ocasión como en septiembre de 1811 - un crecimiento sensible de este cuerpo electoral, aún quedándonos dentro del reducido ámbito de los vecinos. Que nos hallamos en ese espacio social tan peculiar y limitado de la vecindad tradicional nos lo muestran las mismas listas electorales: ni uno solo de los electores deja de ser llamado «don»y los votos son nominales (pese a intentos previos en donde se establecía el secreto de la votación $\left.{ }^{130}\right)$. Y los vocales electos constituyen un muestrario acabado de la gente decente de la ciudad: Vicente Anastasio de Echeverría, Alexo Castex, Marcos Salcedo, Vicente López, José Joaquín Ruíz, José Díaz Vélez, Juan Nepomuceno Solá, Joaquin Belgrano. Lo mismo sucede con la lista de los 33 ciudadanos insaculados ${ }^{131}$.

El 4 de abril, los miembros del ayuntamiento, más los individuos elegidos por insaculación y los representantes de las ciudades del interior (sumados a los de la Banda Oriental), inauguran la Asamblea. Unos días antes, el 28 de marzo, el Triunvirato envia el cabildo una comunicación, de la cual conocemos su borrador ${ }^{132}$ y que señala «los muchos motivos qe. tiene el Govno. para temer con fundamto. que la [lo que sigue en bastardilla y entre paréntesis está tachado en el borrador] (inquietud de algunos hombres agitados de la ambicion) rivalidad y el espiritu de faccion trabajan acaloradamte. por adquirirles influencia en las deliberics. de la proxima asamblea valiendose al efecto del clamor y voceria de (la multitud del Pueblo que crean) un monton de hombres que mezclados en la multitud del Pueblo qe. asistira a las sesiones (la inclinarà) dará a sus solicitudes un aire de popularidad (a que) muy capaz de imponer y de coartar indirectamte. la libertad de los sentimientos y resoluciones de la [¿reunión?] en perjuicio de los ver-

genio y José María- y además, está fechada el 20 de marzo y no el 31; la lista, ubicada en el Archivo Anchorena [AGN-VII-4-2-1], debió haber sido depositada alli probablemente por Juan J. Cristobal de Anchorena, uno de los firmantes al final de la misma y cabildante ese año. ¿Quiere decir esto que hubo una especie de ensayo general de la votación días antes del 31 de marzo?

${ }_{128} A C A$, tomo VI, primera parte, pp. 659-678.

129 Ricardo MARFANY, «El cabildo de mayo», Genealogía. Hombres de mayo, Revista del Instituto Argentino de Ciencias Genealógicas, Buenos Aires, 1961.

130 Recuérdese el texto de la esquela de invitación de agosto de 1811: «la eleccion debe hacerse por villetes secretos, expresando el nombre y apellido del Diputado, debiendo cada elector presentar la esquela con su voto», RMAIE, tomo II, pp. 459-460.

131 Ver la lista en $A C A$, tomo VI, primera parte, p. 685, esta lista es un muestrario del gotha político porteño de esos años: Alagon, de Luca, Domingo Belgrano, Galup, Gomensoro, de Elía, Cossío, Escalada, Segurola, Dorrego, Castro, Ugarteche, Herrera, Espinosa, Grandoli, Argerich...

132 En AGN-X-6-6-1. 
daderos intereses dela Patria y tal vez de su misma existencia politica, quando como V.E. sabe las peligrosas circunstancias en qe. se halla el Estado y los riesgos muy ajenos del conocimto. dela multitud». Por lo tanto, «ha determinado en acuerdo de esta fecha que las sesiones de la proxima asamblea se hagan privadas [...] tomando V.E. quantas medidas estime convenientes a evitar la perturbacion de una voceria tumultuaria».

¿Cuál es ese vocerío tumultuario que teme el Triunvirato (¿o se trata en especial de Rivadavia?) en ocasión de las sesiones de la asamblea? ¿Sería la oposición de Monteagudo y sus amigos ${ }^{133}$ ? ¿O de esos hombres de la orillas que habían participado en los hechos del 5 y 6 de abril? No podemos dar una respuesta satisfactoria. El 3 de abril, se amenaza «con el último suplicio» — es decir, con la pena de muerte - a quienes con «espiritu de Partido» y «abusando del candor y la simplicidad de los hombres incautos» perturbasen el orden ${ }^{134}$. Sabemos ya cómo terminó esta asamblea: el 6 de abril se autodeclaró suprema y ese mismo día ante «aquella escandalosa resolucion» el Triunvirato la disuelve... ${ }^{135}$ Asi finalizó esta primera experiencia congresal del Río de la Plata y la reacción «popular» fue negativa, como lo relata con honestidad Monteagudo - pese a estar de acuerdo con la medida - «El pueblo recibe con una furiosa sorpresa esta acontecimiento y casi todos gritan el gobierno es un déspota y el derecho del mas fuerte es el único que se sostiene» ${ }^{136}$

\section{CONCLUSIONES}

No pasaron dos años desde el 25 de mayo de 1810. Como se puede comprobar, los caminos en búsqueda de la representación no fueron lineales y se presentan en forma harto tortuosa, dando sinuosas vueltas y revueltas. Hemos visto desfilar un sombrero en Cochabamba, un cántaro en Mendoza, un saco y un «barrilete» ${ }^{137}$ en Buenos Aires, una vasija en La Plata, una copa de cristal en San Juan, ejerciendo todos la función de urna electoral. A tantos objetos receptores de votos, les correspondieron otras tantas formas de ordenar la elección y de conformar un cuerpo electoral determinado. La búsqueda del individuo/ciudadano dio algunos pasos hacia adelante y varios hacia atrás. De la abierta experiencia del cabildo

${ }^{133}$ El 25 de marzo, según dice el propio Monteagudo en el primer número de Martir o Libre «ha resuelto el gobierno suspender la edicion de los periodicos semanales, que se daban en esta capital, sostituyendo una gazeta ministerial», Martir o Libre, Buenos Aires, domingo 29 de marzo de 1812 , p. 1

${ }^{134} A C A$, tomo VI, primera parte, p. 684.

135 Ibidem, pp. 693-699.

136 Martir o Libre, 3, lunes 13 de abril de 1812, p. 21

${ }^{137} A C A$, tomo VI, primera parte, p. 681, suponemos que se trata de un barrilito. 
mendocino del 22 de septiembre de 1810, a la menguada reunión cordobesa de febrero de 1812, hay un buen trecho, pero se lo ha recorrido a paso de cangrejo.

En realidad, la unica línea que parece dibujarse es el temor creciente que tiene un reducido círculo en Buenos Aires acerca de la expresión libre de la opinión de «los Pueblos»y de allí las crecientes limitaciones a esa expresión: exclusión de las villas secundarias en el proceso electoral de cara a la asamblea, determinación restrictiva de las formas de elección de los representantes del interior a la asamblea de 1812, fallido experimento de las juntas provinciales, disolución de esa primera asamblea en abril de 1812. Tampoco apreciaba el grupo cercano al poder en Buenos Aires, la voz de aquellos nuevos sectores sociales de la ciudad que se extendían más allá de los que habitaban ese centro, evocado por la frase de Ricardo Levene. Las «orillas» y los «suburbios» plebeyos con sus hombres «de poncho y chiripá», eran ya objeto de inquietud y de zozobra. Esas «gentes colecticias de las clases que habitaban en los subúrvios» y esa multitud que se congregaba «sin conciencia propia de lo que hacía» (López dixit) parecen constituir un ente sociológico totalmente antitético a aquel otro, conformado por los virtuosos individuos/ciudadanos que la experiencia iniciada en mayo de 1810 buscaba edificar afanosamente. Un ente amorfo, compuesto de hombres candorosos e incautos, es decir, una masa ignara, sin discernimiento e inconciente. George Rudé, E.P. Thompson y otros han expuesto ya en varios estudios lumino$\operatorname{sos}^{138}$ de que modo podemos incorporar a estos fenómenos sociales en un enriquecimiento del análisis histórico (y por lo tanto, también en el estudio de las variadas formas que puede adquirir la representación ${ }^{139}$ ), alejándonos así de los clichés que nos transmiten Núñez, Beruti, López, Mitre, Levene, Palcos.

Los hechos de 1820 (derrota porteña y surgimiento de las autonomías provinciales) como los de los años 1826-1828 - fallida experiencia presidencial unitaria y fusilamiento del gobernador Manuel Dorrego- parecen vislumbrarse con claridad en este horizonte estrecho en el que Bernardino Rivadavia y sus camaradas políticos pretendían encerrar la aventura revolucionaria. Tanto los hombres del interior, como los plebeyos habitantes de los suburbios y de la campaña, también pretenderán hacer sentir su voz. Y dirigidos por líderes políticos un poco más perspicaces que aquellos que conformaban el círculo rivadaviano, actuarían en consecuencia.

138 George RUdÉ, La multitud en la historia, Buenos Aires, Siglo XXI Argentina, 1971; Edward Palmer THOMPSOn, Costumbres en común, Barcelona, Crítica, 1995; Arlette FARGE y Jacques ReVel, Lógica de las multitudes. Secuestro infantil en París, 1750, Rosario, Homo Sapiens, 1998.

${ }^{139}$ Nuestro lamentado colega François-Xavier Guerra insistió mucho, en sus (helas!) últimas conferencias acerca de la necesidad de tomar en cuenta entre las formas de representación también aquellas manifestaciones que van más allá de todo sistema electoral. 
Following the track of a number of studies on the early forms of representation in Iberian America, we will show how a detailed anaylisis of the first elections in the Rio de la Plata may contribute to widen our knowledge of "political representation» and "citizenship» during the two first revolutionary years. Setting off from the vacatio regis, it will be analysed in which way the Buenos Aires elites made efforts to keep the independent process under control. While this aim was achieved, the price paid for it would entangle serious consequences for the later evolution of the Rio de la Plata area.

Key words: Independence revolution, representation, citizenship, elections, peoples, main cities, elites, subaltern gourps.

Fecha de recepción: 14 de Enero de 2003.

Fecha de aceptación: 28 de Septiembre de 2003.

R. I., 2004, n. $^{\circ} 231$ 